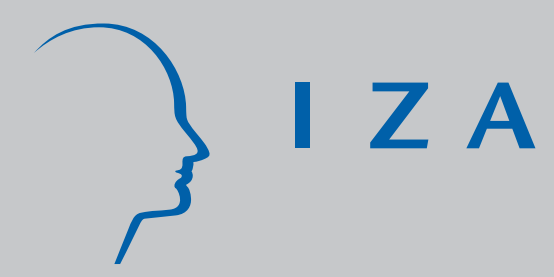

IZA DP No. 1631

Variations in the Wage Returns to a First Degree: Evidence from the British Cohort Study 1970

Massimiliano Bratti

Robin Naylor

J eremy Smith

J une 2005 


\title{
Variations in the Wage Returns to a First Degree: Evidence from the British Cohort Study 1970
}

\author{
Massimiliano Bratti \\ University of Milan \\ and IZA Bonn \\ Robin Naylor \\ University of Warwick \\ Jeremy Smith \\ University of Warwick
}
Discussion Paper No. 1631
June 2005

\author{
IZA \\ P.O. Box 7240 \\ 53072 Bonn \\ Germany \\ Phone: +49-228-3894-0 \\ Fax: +49-228-3894-180 \\ Email: iza@iza.org
}

Any opinions expressed here are those of the author(s) and not those of the institute. Research disseminated by IZA may include views on policy, but the institute itself takes no institutional policy positions.

The Institute for the Study of Labor (IZA) in Bonn is a local and virtual international research center and a place of communication between science, politics and business. IZA is an independent nonprofit company supported by Deutsche Post World Net. The center is associated with the University of Bonn and offers a stimulating research environment through its research networks, research support, and visitors and doctoral programs. IZA engages in (i) original and internationally competitive research in all fields of labor economics, (ii) development of policy concepts, and (iii) dissemination of research results and concepts to the interested public.

IZA Discussion Papers often represent preliminary work and are circulated to encourage discussion. Citation of such a paper should account for its provisional character. A revised version may be available directly from the author. 


\section{ABSTRACT \\ Variations in the Wage Returns to a First Degree: Evidence from the British Cohort Study 1970*}

As in many other countries, government policy in the UK has the objective of raising the participation rate of young people in higher education, while increasing the share of the costs of higher education paid by students themselves. A rationale for the latter element comes from evidence of a high private return to university undergraduate degrees. However, much of this evidence pre-dates the rapid expansion in the graduate population. In the current paper, we use evidence from a cohort of young people born in Britain in 1970 to update influential evidence on returns to a first degree based on a previous 1958 birth cohort. We also analyse variations in returns by degree subject and by class of degree. Our analysis incorporates proxying and matching, control function and propensity score matching methods. Among other results, we find (i) that the returns to a first degree for men changed very little across the two cohorts while the return for women declined substantially and (ii) evidence of differences in returns to a first degree according to subject area of study and class of degree awarded.

JEL Classification: J3, J4, 12

Keywords: degree, return, subject, class, UK, university

Corresponding author:

Massimiliano Bratti

DEAS

Università degli Studi di Milano

Via Conservatorio 7

20122 Milano

Italy

Email: massimiliano.bratti@unimi.it

\footnotetext{
* We would like to thank participants to seminars at CentER (Tilburg University) and the University of Pavia, and Martyn Andrews, Arnaud Chevalier, Luca Flabbi, Susan Harkness, Derek Leslie, Pedro Martins, Peter Sloane, Mark Stewart, Jan van Ours, Anna Vignoles and lan Walker for helpful comments on early drafts of this paper. The usual disclaimer applies.
} 


\section{Introduction}

Higher education policy in Europe is in flux, not least in the UK which has witnessed considerable and ongoing policy change over the last half-century. One aspect of the UK experience has been a steady shift in the burden of funding higher education (HE, hereafter) away from the taxpayer and towards students and their families. Maintenance grant provision has been removed substantially and has been replaced by a system of repayable loans. Furthermore, since 1998, uniform university tuition fees have been paid by all full-time UK university students from within the European Union. Following recent legislation, universities will be able to charge top-up fees up to a regulated maximum, differentiated by university and by course, from Autumn 2006. ${ }^{1}$ Contemporaneously, there has been a significant expansion in the HE participation rate since the late 1980s, associated both with a reduction in the prior academic performance required for university admission and in the unit of resource in the teaching of university undergraduates.

In this context of ongoing policy change, it is important to examine the magnitude of private returns to $\mathrm{HE}$ and the extent to which they have changed over time. Using data on the 1958 British birth cohort from the National Child Development Study (NCDS), Blundell et al. (2000) report an estimated return to a degree of around $17 \%$ for men and $37 \%$ for women, relative to a control group who obtained one or more A-levels (the highest secondary school qualification) but who did not proceed into HE. In part, estimates of sizeable private returns to university degrees have been cited as evidence in support of policies shifting the burden of costs on to students. Graduates in the cohort analysed by Blundell et al. (2000) would most typically have graduated circa 1979, at just about the time that public sector financial support to university students began to decline significantly. Also at this time, UK government policy changes sought to raise substantially the HE participation rate. Rapid expansion of student numbers since the early

\footnotetext{
${ }^{1}$ Early indications suggest that all but a tiny minority of UK HE institutions will charge the maximum fee of $£ 3,000$ per student per annum, for all courses. Effective differentiation is likely only if the ceiling price is raised, though the legislation has ruled this out prior to 2010 .
} 
1980s is likely to have exerted downward pressure on average returns to a degree. Against this, skill-biased technical change (SBTC) during the last two decades of the twentieth century is likely to have increased the demand for graduate labour. The direction of the net effect of these changes on graduate returns is ambiguous. It seems timely, therefore, to update the estimates obtained by Blundell et al. (2000) with the application of their analysis to data for a more recent cohort. We also note that, while research has concentrated on average returns to qualifications, the issue of variations according to level of performance, given qualifications, is under-explored. In the current paper, we examine both the average returns to a degree and also variations by specific factors. In particular, we address the argument that over a period in which the graduate population has expanded, betterperforming graduates might have experience a wage premium to a 'good' degree performance (see Naylor and Smith, 2004).

Section 2 of the paper provides a brief review of evidence on trends in the returns to a degree in the UK. The subsequent analysis conducted in this paper is based on data from the 1970 British Cohort Study (BCS70). This cohort would, typically, have graduated circa 1991, some 12 year after the 1958 cohort analysed in Blundell et al. (2000). In view of the various supply and demand-side changes occurring between the late 1970s and the early 1990s and their likely effect on graduate returns, this 1970 cohort is interesting to contrast with the 1958 cohort. It is also of particular interest to address the question of how returns to higher education vary by specific observed characteristics. In the current paper, we focus on the issue of how returns to a degree vary with both (i) the class of degree awarded and (ii) the subject of the degree studied.

Variation in returns by class of degree has received relatively little attention in the literature. ${ }^{2}$ This is largely a consequence of the fact that few data-sets contain adequate information on class of degree awarded. The issue is of interest, however, for two reasons. First, if there is significant variation by degree class around the average return to a degree, then the

\footnotetext{
${ }^{2}$ In the UK degrees are classified in descending order as first, upper second, lower second, third class, non-honour degrees, fail. First and upper second class degrees are often referred to as 'good' degrees.
} 
investment in HE could yield a low return to poor-performing students. Shifting the burden of university fees further towards students then risks generating a greater disincentive to HE participation than would be the case with relatively little variation around the average: a narrow focus on the average return may be inadequate for policy purposes. Second, it is of general interest to examine the extent to which the labour market rewards the graduate's class of degree. Estimates of returns to education have tended to focus on years of schooling or on levels of qualifications. Yet, as there is substantial clustering of labour market entrants on both these criteria, one would expect employers to discriminate between candidates on factors such as grades achieved: that is, on degree class awarded in the context of higher education in the UK. This itself is likely to vary with the proportion of a cohort investing in a university degree.

Variation in returns by degree subject has received more attention, as we discuss in more detail below. Since the introduction of flat-rate fees, a number of authors have argued that there is a theoretical case for differentiating fees by subject (see, for example, Greenaway and Haynes, 2003). The strength of the case for differentiating fees depends in part on the strength of evidence that the return to a degree varies by subject studied and/or by institution attended. At the time of writing, legislation to introduce differential fees has just passed through the UK parliament. The proposed legislation would permit fees to vary by university and by course. In the current paper, we provide a brief review of the literature on variations of wage returns by undergraduate degree courses and degree performance and present new estimates on log-wage premia by subject studied and degree class. Our data do not enable us to estimate ceteris paribus variations in returns by institution of study. On this issue, see Chevalier and Conlon (2003).

The rest of the paper is organised as follows. Following a brief survey in section 2 of recent evidence on returns to HE in the UK, section 3 provides a description of the data set and the sample selection procedure used in our analysis. In section 4 , we discuss the issue of the endogeneity of educational qualifications and describe a way of addressing it, the so-called proxying and matching method. In section 5, we present a replication study of Blundell 
et al. (2000) comparing results for the 1958 and the 1970 birth cohorts using the proxying and matching method. Section 6 reports estimates of the return to a first degree based on our most preferred specifications for the 1970 cohort and provides evidence on variations in returns according to degree class awarded and area of subject studied. Section 7 describes an alternative way of addressing the issue of endogeneity, using the so-called control function approach, while section 8 explores the possibility of heterogeneity in the returns to a first degree according to observed characteristics in a heterogeneous treatment framework. Finally, section 9 summarises the main findings and concludes.

\section{Evidence on the returns to a degree in the UK}

One of the most influential analyses estimating the returns to a degree in Britain is that of Blundell et al. (2000). This study used data from the National Child Development Study (NCDS), an ongoing survey of all individuals born in Britain in the week $3^{r d}-9^{\text {th }}$ March 1958. The data are particularly rich in information useful in the estimation of returns to education, such as ability measures, educational qualifications and family background characteristics. The approach adopted in Blundell et al. (2000) is to compare individuals with HE qualifications with those individuals who did not go on to HE but whose secondary school qualifications (A-levels) would have permitted them admission to HE. Hence, the estimated returns are to be interpreted as conditional on having performed well at secondary school.

As is well known, the estimation of educational returns is potentially susceptible to problems of endogeneity bias arising from the fact that typically unobserved - and hence omitted - characteristics (such as ability) affecting educational outcomes are also correlated with subsequent labour market outcomes. Blundell et al. (2000) exploit the fact that the NCDS data are rich in information on typically unobserved characteristics and include these as regressors in their log-wage equations. This proxy and matching approach assumes that HE decisions are made on the basis of (i) observed and included characteristics and/or (ii) unobserved characteristics which are well proxied by the included observed variables. If these assumptions are valid, 
then the estimated returns are consistent. We discuss these issues in more detail in section 4 of the paper.

Blundell et al. (2000) estimate the impact of different levels of HE on gross hourly wages at age 33. They estimate the raw returns to a first degree $^{3}$ to be $21 \%$ for men and $39 \%$ for women, relative to the control group of cohort members with A-level qualifications but without HE. When the full set of controls is included in the estimation, the estimated returns to a first degree fall substantially in the case of men - to only $12 \%$ - and only slightly in the case of women - to $34 \%$. Without controls for ability at age 16 or A-level score, the estimated returns are $17 \%$ for men and $37 \%$ for women. The ceteris paribus returns to higher degrees (such as Master and Doctoral degrees) are estimated to be $8 \%$ for men and $32 \%$ for women, relative to those with just A-levels, when all controls are included.

Blundell et al. (2000) also report different returns estimated for different courses studied at HE, finding that returns for men tend be relatively low in Biology, Chemistry, Environmental Sciences, and Geography and for women tend to be relatively high in Education, Economics, Accountancy and Law and in 'Other social sciences'. As the authors acknowledge, splitting the NCDS graduate sample by subject leads to relatively small cell sizes and hence produces poor precision in the estimates at the subject level.

As Blundell et al. (2000) also acknowledge, analysis of wage returns to an undergraduate degree based on the NCDS cohort refers to individuals who, typically, were making HE decisions in the late 1970s and graduating around 1980. As we noted earlier, there have been substantial changes in the HE sector and in the graduate labour market in the last two decades and hence it is interesting to compare and contrast the results obtained for the 1958 birth cohort with results based on the analysis of the more recent 1970 birth cohort. This forms a principal focus of the current paper. We are also particularly interested in how returns to a degree might vary with the class of degree awarded and with the HE subject studied.

\footnotetext{
${ }^{3}$ Heckman et al. (2003) stress that in estimating rates of return it is necessary to take account of, among other factors, the direct and indirect costs of schooling, taxes, and the length of working life. In what follows, we often use the term wage 'return' although it should be interpreted in the narrow sense of a log-wage premium.
} 
There have been a number of studies using a variety of data sources in order to estimate the private return to a university first degree in the UK. Dearden (1999), also using NCDS, reports an estimated wage return to a degree of $17 \%$ for men and of $32 \%$ for women, based on OLS, and also finds that the conventional OLS estimates are reasonable approximations of the true causal impact of higher education on wages. Harkness and Machin (1999) examine changes in wage premia to education in the UK between 1974 and 1995 using data from the General Household Survey (GHS). They report time-varying estimates of the wage premium associated with various educational qualifications. For the period 1979-81, the estimated wage premia to a first degree, relative to A-level qualifications, are $14 \%$ for men and $21 \%$ for women. By the period 1993-95, these estimated premia have risen to $20 \%$ and $26 \%$, respectively. Harkness and Machin (1999) conclude that despite a rise in the relative supply of workers who have a degree in the UK, the fact that the return to a degree was rising in the 1980s and 1990s suggests that relative demand - for example induced by SBTC - rose faster than relative supply. Walker and Zhu (2001), using Labour Force Survey (LFS) data from 1993-2000, estimate the average return to a degree over A-level to be approximately $25 \%$ for men and $30 \%$ for women. The return to a first degree was $20 \%$ for men in 1993 and about $26 \%$ in 2000, while for women it was $33 \%$ in 1993 and about $25 \%$ in 2000. These figures suggest, therefore, an increase over time in the return to HE for men and a decrease for women.

The differences in the estimates from different studies referring to the same period often stem from the specification adopted which in turn depends on the nature of the data used. Longitudinal studies, such as those based on the NCDS or BCS70, are rich in information on family background, abilityrelated and past educational variables, which are important to address the issue of ability bias and whose inclusion often results in a reduction in the estimated return to education (see Card, 1999, and Blundell et al., 2003, among others). For the same reason, the studies using other data sources where these variables are not available (such as the LFS) estimate higher returns. Moreover, Heckman et al. (2003) discussing the differences between cross-sectional and cohort-based estimates of the return to education, sug- 
gest that the latter should be used when the purpose is to estimate historical returns and make comparisons over time, since cohort changes are likely to affect the cross-section estimates slowly as more and more individuals from the new cohorts enter the labour market.

In addition to the study of Blundell et al. (2000), a number of other studies have also investigated the extent to which returns to a university degree vary by subject studied. Because of problems of small cell size, most studies consider broad subject groups. Lissenburgh and Bryson (1996) using the Youth Cohort Study estimate returns of $9 \%$ for Science relative to Arts and Social Sciences for both males and females combined. Harkness and Machin (1999) find that for men Social Sciences always give the highest wage premium with respect to A-level (24.6\% in 1995) while Science ensures the highest premium for women $(44.8 \%) .{ }^{4}$ It should be observed that while male graduates generally do not have statistically significant wage premia from undergraduate degrees in Arts, female Arts graduates earn significantly higher wages in all years considered, especially in 1995 when the wage of Arts graduates is higher than that of Social Sciences graduates (with premia of $31 \%$ and $23.4 \%$, respectively).

Walker and Zhu (2001) use a quite disaggregated definition of subjects (13 in total), but based on their disaggregated estimates, for males (females) in 1999 the returns with respect to A-level are 19\% (41.6\%), 23.7\% (45.8\%) and $4.3 \%$ (20.8\%) for Science, Social Sciences and for Art and Humanities, respectively. ${ }^{5}$ Therefore, both males and females appear to obtain higher returns for Social Sciences degrees. Moreover, women have higher returns than men in all degree subjects, and in particular in Art and Humanities. Neither Harkness and Machin (1999) nor Walker and Zhu (2001) control for family background variables, and this may have inflated their estimates of the return to undergraduate degrees.

One of the problems facing estimates of returns to degrees by subject

\footnotetext{
${ }^{4}$ Including controls for age, age squared, dummies for degree subject, teacher status, region and industry.

${ }^{5}$ Science includes Health, Nursing, Science, Maths, Engineering, Arthitecture. Social Sciences includes Economics, Law and Social Studies. Art and Humanities includes Language, Education, Art and Combined degrees. Their specification includes controls for age, age squared and dummies for marital status, race, union status and region.
} 
studied - where degree subject information even exists in the data - is that of small cell sizes. This problem is overcome when graduate cohort data are used. There are two sources of such data. First, there are follow-up surveys of samples of graduates from the graduating cohorts of 1960, 1970, 1980, 1985, 1990 and 1995. Each of the cohort samples generates, on average, several thousand observations on graduates and their early labour market experiences, including earnings. With these data one can estimate earnings premia by degree subject studied. A second source of graduate cohort data comes from matching administrative data on the entire population of UK university students - as collected formerly by Universities' Statistical Record (USR) and now by the Higher Education Statistics Agency (HESA) - to the information contained in the responses to the first destination survey of all graduates. This matched data-set is very rich in information on graduates' education (including university, course, degree class, pre-university schooling and attainment), personal characteristics and family background. The postuniversity outcome provides information on the graduate's occupation six months after graduation.

Using the follow-up surveys of samples of graduates, Dolton and Makepeace (1990) and Dolton et al. (1990) analyse earnings data from the 1986 survey of one in six of the 1980 UK university graduates (5,002 graduates). Unlike the HESA/USR data, the information on degree, other qualifications and family background do not come from administrative data but from personal recall. Dolton et al. (1990) find significant earnings premia for Science and Social Sciences students compared to Humanities or Education students. A positive wage premium for Mathematics-related degree courses is a common finding in studies using the graduate sample follow-ups: see Chevalier et al. (2000), Belfield et al. (1997), and Battu et al. (1999) for results pertaining to the 1996 follow-ups of the 1985 and 1990 graduate cohorts. Chevalier et al. (2002) analyse 1998 earnings data for a sample of 8,264 graduates from the 1995 graduate cohort. They report that relative returns are highest for Mathematics (at 29\% for men and 19\% for women), compared to the field of Education studies. They make the important point that differences in relative returns across cohorts are to be interpreted with care given differences across cohorts in the method of classifying degree sub- 
jects. Chevalier et al. (2002) provide a comprehensive survey of estimates of returns to HE.

With respect to differences in returns to a degree according to the degree class obtained, Battu et al. (1999), using graduate cohort data, estimate a significant log-wage premium associated with a first class over a lower and upper second class degrees. Naylor et al. (2003), using HESA-USR data for 39,454 individuals responding to the first destination survey of all 1993 graduates, estimate an occupational earnings premium of $3.9 \%(3.6 \%)$ for a first class degree relative to an upper second class degree for men (women). The premium for a first over a third class degree is estimated to be $13.8 \%$ for men and $8.9 \%$ for women. Replicating the analysis on earlier graduate cohorts, Naylor et al. (2003) find that the premium for a first class degree has been growing over time. It is noticeable that while for the earlier cohorts there was no statistically significant premium associated with the class of degree awarded, a significant differential has developed and grown over time. One hypothesis for this is that as the population of graduates has grown, greater importance is attached by employers to the signal emitted by a graduate who has performed well at university. For a more formal treatment of this hypothesis, see Naylor and Smith (2004).

One focus of the current paper is to test for corroborating evidence on the extent of any degree class premium from a different data source. Using BCS70, our attention focuses on a cohort of young people who, typically, would have been graduating in the very early 1990s - the period of time for which Naylor et al. (2003) estimate significant relative premia for a good degree performance.

Finally, we note that there has been some work on the extent to which returns to degrees vary by institution attended. From first destination survey data, Naylor et al. (2003) estimate statistically significant differences, ceteris paribus, in occupational earnings across universities. Chevalier and Conlon (2003), using data from the follow-up surveys of samples of graduates for 1985, 1990 and 1995, conclude that graduating from one of the more highly regarded UK universities (that is, a Russell Group institution) is associated with a wage premium of up to $6 \%$ for men, compared to the default case of having graduated from a new university. From this estimate, 
Chevalier and Conlon (2003) infer justification for a policy of differentiating fees by institution.

\section{Data and sample selection}

In this paper we use data drawn from the BCS70. The BCS70 began in 1970 when data were collected on the births and families of 17,198 babies born in England, Wales, Scotland and Northern Ireland between the $5^{\text {th }}$ and the $11^{\text {th }}$ of April of that year. There are currently five complete follow-up surveys available: at periods $5,10,16,26$ and 30 years after the original survey. In this paper we use data on gross hourly wages collected in the 30-year followup survey, while family background and individual characteristics come from the 10-year follow-up survey. Based on the sample of respondents to the 30year follow-up survey (11,261 individuals), and in analogy with Blundell et al. (2000, p. F84), we select only individuals who have obtained at least one A-level, which is our population of interest, and analyse the return to HE qualifications with respect to those individuals who did not complete any form of HE. As observed by Blundell et al. (2000), individuals with at least one A-level but who did not continue into HE are probably a better comparison group for students undertaking undergraduate degree courses than for those enrolling in courses leading to a non-degree HE qualification, since the latter group usually has non-traditional entry qualifications (i.e. different from the standard A-level qualification). The same can be said for individuals undertaking postgraduate studies, as they must possess a first degree, and for whom individuals with A-levels only are not a very good comparison group. This should be kept in mind when interpreting our empirical results on, for example, postgraduate students. For these reasons in the paper we focus on the return to an undergraduate degree.

From our sample of individuals who have at least one A-level (a total of 2,755 cases), we focus on those who also replied to the 10-year follow-up survey $(2,553)$. This is done since in the estimation of the log-wage regressions we will include individual and family background control variables which are provided by the 10-year follow-up. Among this sub-set we choose individuals who worked as employees full-time or part-time (2,092 individuals) and 
exclude those individuals with missing data on their gross hourly wage (114 cases dropped). In order to maintain the sample size, and in analogy with Blundell et al. (2000), individuals with missing values for other variables were kept in the data set and missing value dummy variables were included in the regressions. The final sample includes 1,978 individuals.

Since our analysis examines a sample derived from matching the 10-year and 30-year follow-up surveys of the BCS70, it is useful to show how our sample compares with respect to the 30-year follow-up survey. In Table 1 we report the distribution of educational qualifications and the sample mean of gross hourly wages in natural logarithm for various samples. From Table 1 the number of matches between the 30-year and the 10-year follow-up surveys is higher than that between the 30-year and the 16-year follow-up surveys by about 8.5 percentage points. Together with a higher incidence of item-non response in the 16-year wave, this is the main reason for our use of family background variables at age 10, along with the availability of an indicator of 'innate' or 'early' ability (the British Ability Scale score, see Elliot et al., 1979) at this age. As can be seen from Table 1 the distribution of educational qualifications is very similar across samples. This evidence suggests that survey non-response and panel attrition, although of nonnegligible size, might be random with respect to educational qualifications. In relation to wages, means are very similar across samples. In particular, the average of the natural logarithm of gross hourly wages is 2.270 in the $30-$ year follow-up, 2.267 in the 30-year and 10-year matched sample, 2.267 in the 30 -year and 16-year matched sample and 2.265 in the sample of individuals matched in all three waves.

\section{OLS, endogeneity and the proxying and match- ing method}

When we estimate the returns to different educational qualifications, we consider the effect of a multiple treatment, namely educational qualifications, denoted as $j=1, \ldots J$, on individual wages, $w_{i}$. We consider four different educational qualification: A-level only ( $j=1$, the reference group), non-degree 
Higher Education $(j=2)$, undergraduate ( $\mathrm{UG}$, or first) degrees $(j=3)$ and postgraduate $\left(\mathrm{PG}\right.$, or higher) degrees $(j=4)$. If we indicate with $w_{i}$ the gross hourly wage of individual $i$, our model can then be written as follows:

$$
\ln w_{i}=m X_{i}+\sum_{j=2}^{J} b_{j} Q_{i j}+u_{i} .
$$

where $m X_{i}$ is a linear function of the observed variables $X_{i}$, which we will refer to as the no-treatment outcome, $Q_{i j}$ are dichotomous variables assuming value 1 if individual $i$ has as her/his highest educational qualification a qualification $j$ and 0 otherwise, and the $b_{j}$ 's are the effects of these educational qualifications on log-wages, i.e. they are our parameters of interest. We abstract for the moment from problems concerning the correct specification of the no-treatment outcome and assume that a linear function is an appropriate representation of the log-wage data generating process, as is the usual assumption in most of the existing empirical literature on the returns to education. In the case $E\left(u_{i} \mid X_{i}, Q_{i j}\right)=0$, the $b_{j}$ parameters can be estimated without bias using ordinary least squares (OLS, hereafter). Assuming no heterogeneity in the returns to education, the Average Treatment on the Treated (ATT), the Average Treatment on the Non-Treated (ATNT), and the Average Treatment Effect (ATE) all coincide and are recovered by the $b_{j}$ 's.

However, there are several reasons why we may expect a non-zero correlation between educational qualifications and the error term in the log-wage equation. These are outlined, for instance, in Blundell et al. (2003) and include:

1. Ability bias (absolute advantage). We might assume that the error term $u_{i}$ in equation (1) consists of two components, i.e. $u_{i}=\alpha_{i}+\epsilon_{i}$, one reflecting unobserved earnings capacity $\left(\alpha_{i}\right)$, with $E\left(\alpha_{i} \mid X_{i}, Q_{i j}\right) \neq 0$ and the other some unobserved factors uncorrelated with all covariates included in the wage regression $E\left(\epsilon_{i} \mid X_{i}, Q_{i j}\right)=0$. It is the non-zero correlation between unobserved earnings capacity (also referred to in the literature as ability) and education which causes the so-called 'ability bias'. In particular, we may expect high ability individuals both to 
acquire more education and to earn higher wages. Earnings capacity is potentially observed by the individual but not by the analyst;

2. Return bias (comparative advantage). The returns to the different educational qualifications may not be homogeneous across individuals. In this case an individual's return to qualification $j$ can be specified as $b_{j}+b_{i j}$, where $b_{i j}$ is an educational qualification-specific idiosyncratic component and $i$ the subscript for the individual. In this case, we will have a distribution of $b_{i j}{ }^{\prime}$ s. ${ }^{6}$ There is a return bias when $E\left(b_{i j} \mid X_{i}, Q_{i j}=1\right) \neq 0$, i.e. individuals self-select into the different educational qualifications according to their idiosyncratic returns, which depend in turn on characteristics that are observable to the individual but not to the researcher;

3. Measurement error bias. The educational variables may be measured with error. In our case, where education is a categorical variable, measurement error is non-classical and in general it is not possible to say anything on the direction and magnitude of the bias (see Kane, Rouse and Staiger 1999).

In our analysis in the current paper, we focus only on the first source of bias, i.e. ability bias, and assume that the return bias is small or absent for the following reasons. Although heterogeneous returns according to unobserved characteristics may exist, there is a return bias only if individuals are able to predict correctly their idyosioncratic gains in the return distribution, that is they know $b_{i j}$, and use this information to choose their level or type of educational qualification, which is a strong assumption. In this regard, there is an interesting stream of literature on students' income expectations. Betts (1996) using US data finds that students can predict their starting salaries quite well and better than life-time earnings profiles and tend to underestimate wages in fields outside their own. He also finds that the most widely used source of information for wages are newspapers and magazines, which would suggest a substantial homogeneity in income expectations. Dominitz and Manski (1996) find using US data that students are

\footnotetext{
${ }^{6}$ In this specification $b_{i j}$ is a random coefficient.
} 
very uncertain about their own future earnings, both at ages 30 and 40 and tend to be more uncertain about their earnings with a university degree than about earnings with only secondary school. The authors also find substantial heterogeneity in students' beliefs about the actual earnings distribution. Wolter and Zbinden (2002) use Swiss data and find that students' expectations are much closer to actual wages at the time of graduation while their prediction errors are higher when considering the pattern of wage increase during the first 10 years of their careers.

Therefore, most studies show that individuals are able to predict more accurately their starting wages, while their predictions are much less precise for earnings later on in the life-cycle, which we consider in this paper since individuals from the BCS70 with a first degree typically have in 2000 about 9 years of labour market experience. Blundell et al. (2003) using NCDS data find the absence of both an ability and a return bias when interactions between educational qualifications and individuals' observed characteristics are included in the log-wage equation estimated through OLS. Unfortunately, they are able to provide this evidence only in the case of a single treatment model (first degree vs. other educational qualification) since the size of their sample, which is very similar to ours, does not allow the exploration of heterogeneity of returns with respect to observed characteristics when considering a multi-treatment model in a regression framework. ${ }^{7}$ Finally, we think that the third source of bias should be less severe when including educational qualifications, as we do, rather than the number of years of schooling. ${ }^{8}$

A possible approach to tackle endogeneity issues when the data set is particularly rich, as in our case, is the so-called proxy and matching method. This is the approach followed in Blundell et al. (2000) and in the replication of their analysis on BCS70 data reported in section 5. This consists of including among the individual characteristics $X_{i}$ factors which might affect both the educational qualification achieved and wages, and by proxying the

\footnotetext{
${ }^{7}$ We tried to interact the educational qualifications with social class, however probably due to small cell size the interactions generally turned out not to be statistically significant.

${ }^{8}$ For the simple fact that recall errors should be only minor for the highest educational qualification achieved by age 30 .
} 
unobserved component $\alpha_{i}$ with observed factors highly correlated with it, so that $u_{i}=\epsilon_{i}$. As observed in Blundell et al. (2000) equation (1) can be viewed as a form of regression-based linear matching. Thus, the estimates presented in sections 5 and 6 can be argued to have been obtained using a method which addresses the issue of endogenous ability bias.

\section{Comparison with the 1958 British Cohort}

In this section we compare BCS70 and NCDS data, the latter referring to the 1958 British cohort - analysed in Blundell et al. (2000). Comparing the first column of Table 1 - with the descriptive statistics reported in Blundell et al. $(2000, \text { p. F } 86)^{9}$ we observe a reduction in both the proportion of people with A-levels not completing any form of $\mathrm{HE}$, and in the proportion of individuals taking non-degree HE qualifications. We also note a large increase in the proportion of individuals completing first degrees, and a slight increase in the proportion of people with postgraduate degrees. These figures are consistent with the widening access to HE that took place in the UK during the 1980s, when graduates of the 1970 British cohort typically entered HE. Our data show a particularly marked increase in the supply of female graduates with respect to the 1958 cohort. On the basis of the observed increase in the number of graduates, we would expect a reduction in the return to a first degree, ceteris paribus. However, demand-side forces, working, for example, through skill-biased technological change (SBTC) might have counteracted this tendency and brought about an increase in the return to a first degree.

In order to gauge the extent of any change in the return to a first degree between the 1958 and the 1970 cohorts, we attempt to replicate the analysis in Blundell et al. (2000). We have included the same kind of explanatory variables and used the same classification of educational qualifications as those underlying the log-wage equations estimated in Blundell et al. (2000) ${ }^{10}$ in order to ensure as high a degree of comparability as possible.

\footnotetext{
${ }^{9}$ The percentage of men (women) completing non-degree HE, a first degree or a higher degree are $21 \%(25 \%), 38 \%(33 \%)$ and $17 \%$ (14\%), respectively, in the sub-sample of the NCDS considered by Blundell et al. (2000).

${ }^{10}$ PG degree: all higher degree qualifications; UG degree: first degree; Non-degree HE:
} 
Inevitably, however, there are some coding and other data differences across the two surveyed cohorts. For example, it should be noted that the wage data in the BCS70 refers to age 30, while Blundell et al.'s (2000) analysis of NCDS refers to age 33. This fact might have some implications for the comparison between the two cohorts if returns to educational qualifications vary with age: that is, if education has not only an intercept but also a slope effect on wages. Although the age difference between the two cohorts is only minor, to have an estimate of the likely differences in the return to education between age 30 and age 33 we have examined data from the UK Quarterly Labour Force Survey (QLFS). We constructed a pooled sample of selected individuals appearing in the first wave of each quarter of the QLFS $2000,{ }^{11}$ providing gross hourly pay data and with at least A-level or equivalent qualifications. Relative to a control group of individuals with only A-levels, ${ }^{12}$ the estimated returns to a degree or equivalent for men were 0.39 (p-value: 0.00 ) at age 30 and 0.42 (p-value: 0.00 ) at age 33 . The estimated returns to a degree for women were 0.50 (p-value: 0.00 ) at age 30 and 0.54 (p-value: $0.00)$ at age $33 .{ }^{13}$ Our estimates suggest that although the wage returns to a degree with respect to A-levels at age 33 tend to be higher than at age 30 the difference is only minor and of an order of magnitude of 3-4 percentage points. Hence, our conclusion is that wage returns to a degree at age 30 and age 33 are likely to be very similar and that a comparison between NCDS (age 33) and BCS70 (age 30) is legitimate.

Following Blundell et al. (2000) we estimate a gross hourly wage regresnon-degree NVQ Level 4, HNC/HND, BEC/TEC higher, university diploma or certificate, professional or nursing qualifications, HE diploma or certificate, C\&G full technology certificate or insignia award in technology; A-level: A-level qualification, Scottish Higher or Scottish Six form college.

${ }^{11}$ This is done to avoid double counting of individuals because respondents are interviewed on five separate occasions, starting from the quarter they enter the survey and then in the next subsequent four quarters and since Spring 1997 they are asked about their earnings in their first and final interviews.

${ }^{12} \mathrm{We}$ use the derived variable hiquald provided in the QLFS, where first degrees and equivalent include UG and PG degrees, while higher education includes non-degree HE.

${ }^{13}$ The regression for men included 225 individuals at age 30 and 261 individuals at age 33, that for women included 207 individuals at age 30 and 228 at age 33 . The full regression results are available upon request. 
sion in natural logarithms following three specifications: ${ }^{14}$

1. including only educational qualification dummies;

2. including educational qualification dummies, plus British Ability Scales scores in the non-verbal and verbal questions separately, regional dummies and school type, all at age 10;

3. including all the variables in the previous specification, plus family background variables at age 10 (parental education, parental social class, number of older siblings, number of younger siblings, house ownership), socio-demographic variables (\% of children's fathers in Social Class I and \% of children's fathers in Social Classes IV-V in the child's school at age 10), school attendance at age 10 (number of missed days of school), employer characteristics in 2000 (firm size, union membership dummy, private sector dummy).

The estimates from the three specifications conducted on BCS70 are reported in tables 2 and 3, for men and women respectively, alongside the equivalent estimates for the NCDS 1958 cohort reported in Blundell et al. (2000), indicated with 1', 2' and 3', respectively. From specification 1, males with a first degree earn significantly more than those with just A-levels: the wage return is 0.20 . This is remarkably close to the point estimate of 0.21 for the 1958 cohort. In general, the returns to the other types of HE appear to have decreased over time. For females, the coefficients of all educational dummies are statistically significant. In specification 1 , the estimated wage return associated with an undergraduate degree is 0.27 , compared to an estimate of 0.39 for the 1958 cohort.

Typically, adding control variables leads to reductions in the estimated returns to the different HE qualifications. In the most complete specification, specification 3 , the return to an undergraduate degree is 0.15 for males and 0.23 for females. The equivalent figures from the corresponding specification in Blundell et al. (2000, p. F90) are 0.17 for men and 0.37 for women.

\footnotetext{
${ }^{14}$ We are not able to consider specification 4 in Blundell et al. (2000, p. F91, Box 1) since we cannot compute the UCAS score, as A-level grades are not available in the BCS70 data set.
} 
It appears, then, that while the private return to a first degree for men is remarkably similar in the two British cohorts (1958 and 1970), there is a striking fall in the return to a first degree for women in the 1970 cohort. For men, the results are consistent with the idea that the opposing supply-side and demand-side pressures on returns to a first degree have approximately balanced each other. We note that the 1970 birth cohort would, typically, have graduated in the early 1990s and that their earnings are observed in 1999/2000. The 1958 cohort would have graduated around 1980 and their earnings were observed in 1991. Hence, our results call in to question the findings based on LFS and GHS data of a rise in the return to a degree for males during the 1980s and 1990s. Our estimate of a log-wage premium of 0.20 for males, based on specification 1 , is very similar to those reported in our survey of UK evidence in section 2. However, the fact that when we introduce other control variables - not typically observed in other datasets in specification 3 the estimate falls to 0.15 suggests that other studies have tended to over-estimate the return to a degree for men in the UK.

For women, our finding that the estimated return to an undergraduate degree has fallen between the two cohorts is consistent with results reported in Walker and Zhu (2001). There are various interpretations which one could put on this. First, we note that the very high estimated returns for female graduates in the earlier (NCDS) cohort could be interpreted as arising in part from greater gender pay discrimination at lower education levels. Some evidence in this direction is provided by Makepeace et al. (1999), who analysed the 1948 and the 1958 British cohorts and found a positive effect of the Equal Pay Legislation in reducing gender pay gaps and that the reduction was relatively higher at the bottom quantiles of the earnings distribution. Hence, the legislation was particularly effective in reducing the gender pay differential for low paid women, who were also likely to be less educated women. The same trend has been confirmed for more recent years by Harkness (2004), who finds that women in the lowest percentile of the earnings distribution have improved their relative pay with respect to men and that this was mainly due to an increase in demand for low paid service sector and non-routine occupations (see also Goos and Manning, 2003) and the introduction of the minimum wage. Harkness (2004) finds that in the 
1990s and beyond the biggest gains in relative earnings have been for less educated women.

Second, we note that the expansion in the number of graduates between 1990 and 2000 was a particularly female phenomenon. Thus, to the extent that there was a relative shortage of female graduates in the labour market in the early 1990s, this was likely to have been less true for 2000 since the supply-side shift in the number of graduates was much greater for females than for males. To the extent that the graduate labour market is 'genderneutral', this should not have implications for the magnitude of any gender difference in returns to a degree. However, to the extent that male and female graduates are either not perfect substitutes or do not have equal preferences over jobs, then it is likely that the relative increase in the supply of female graduates will have been associated with the observed reduction in the gender difference in the return to an undergraduate degree. Evidence of a reduction in the wage return to a first degree for women from recent birth cohorts is also observed by Sloane and O'Leary (2005) who using LFS data report a median return for women of $0.43,0.35$ and 0.22 for the $1950 \mathrm{~s}$, the 1960s and 1970s birth cohorts, respectively. By analysing the effect of supply and demand factors they observe a reduction in graduates' unemployment rates overtime, which suggests an increase in demand, but at the same time also evidence of a reduction in wage returns, which they attribute to the particularly fast increase in the number of female graduates entering the labour market recorded in recent years. Chevalier et al. (2004), also using LFS data, observe for more recent cohorts a reduction of the wage return to a first degree both for men and women but particularly pronounced for the latter (0.40 for the cohort 1958-68 and 0.30 for the cohort 1969-1977). They interpret differences in returns by cohort as evidence that younger generations of graduates are not a perfect substitute for older generations.

The supply-side argument is sometimes presented as associated with a form of over-education: see, for example, Dolton and Vignoles (2000), Hartog (2000) and Chevalier (2003). Similar findings of an under-utilisation of graduates' skills in a context of expanding student numbers are reported in Rigg et al. (1990), Mason (1995) and Green et al. (1999). We note however that the very similar estimated return for men in the 1958 and the 1970 
birth cohorts, runs counter to the idea of a general level of over-education across both genders.

Another possible explanation for the fall in the female return to HE is the changing composition of female graduates in terms of degree subjects. Sloane and O'Leary's (2005) analysis indicates an increase between 1994 and 2002 in the fraction of female graduates in Medicine and related subjects, and in Business and Finance and a reduction in Education, Maths and Computing and Sciences. However, the change in the breakdown by subject for female graduates' does not appear to be dramatic, and there appears to have been a general fall in women's returns across most subjects. Interestingly, the fall in returns was particulary marked in typically femaledominated subjects such as Sciences, Education and Arts which represent over $40 \%$ of the stock of female graduates.

We note that our analysis of HE returns is conditional on employment: that is, we do not address the issue of selection into employment. This is made mainly to preserve comparability with almost all studies reviewed in section 2. Although the ratio between the number of employees and the total population tends to be very similar for men irrespective of the highest educational qualification possessed (in the BCS70: 83.6\%, 87\%, 84.6\% and $89.7 \%$ for individuals with only A-level, Non-degree HE, UG degrees and PG degrees, respectively), for women this ratio tends to differ more markedly by level of education (in the BCS70: 70.90\%, 80.93\%, 83.47\% and $83.47 \%$ for individuals with only A-level, Non-degree HE, UG degrees and PG degrees, respectively) and the issue of self-selection into employment might be relevant. As it is likely that women who can command comparatively higher wages in the labour market are more likely to be employed, our estimates might understate the return to a first degree when considering the whole female population. This suggests another possible explanation for time changes in the returns to an UG degree for women, stemming from the change in the composition of the control group. For instance, an increase in women's labour force partipation is likely to have increased participation of less educated women disproportionately, as women with higher education were anyway more likely to be attached to the labour market. Without controls for selection into employment, we would therefore have expected an 
increase rather than a fall in the estimated returns to a first degree, because of relatively more employed women with A-levels only and low earnings capacity in the 1970 cohort than in the 1958 cohort.

\section{Preferred estimates using the proxying and match- ing method}

\subsection{Return to a first degree}

We have already said that the application of the proxying and matching method requires the availability and inclusion among the $X_{i}$ 's of a wide set of individual characteristics affecting education and wages. In section 5 , our choice of specification was dictated by our attempt to replicate the analysis of Blundell et al. (2000). In this section, we present estimates of the return to a degree based on our most preferred specifications for the BCS70 dataset, under a proxying and matching approach.

In particular, we include among the $X_{i}$ 's in the starting specification:

1. personal characteristics: region of residence at age 10, ethnicity.

2. family background variables: father's education and social class, mother's education and social class, presence of the mother, presence of the father, home ownership, family income, number of younger siblings, number of elder siblings, parental interest in child's education, all at age 10 .

3. age 10 school variables: school type, school attendance, $\%$ of children whose father is in Social Class I (professionals)and \% of children whose father is in Social Classes IV-V (partly skilled and unskilled, respectively) in the school attended.

4. ability at age 10: score in the verbal and non-verbal sections of the British Ability Scales questionnaire, as proxies for verbal and quantitative innate (or early) ability.

Therefore, we include most of the variables already included in the replication reported in the previous section but, unlike Blundell et al. (2000), 
we do not include employer characteristics for two main reasons. First, they may be endogenous in the sense of being choice variables for the individual and jointly determined with wages. Second, employers' characteristics may be affected by educational qualifications, and by excluding them we estimate the 'overall' effect of education, both on wages and on the likelihood of working for certain types of employers (see for instance Blundell et al., 2003, and Pereira and Martins, 2004).

We first estimate the model including all factors 1-4 above in the sample of matched individuals from the 30-year and the 10-year follow-up surveys and perform some F-tests for the significance of the various groups of variables. After selecting a 'parsimonious' specification (specification I), by keeping the groups of regressors statistically significant or only marginally not significant at the $10 \%$ level, we also estimate additional specifications which include past educational variables available from the 30-year follow-up survey. ${ }^{15}$ Specifically, specification II adds:

- S (Supplementary), A (Advanced) and AS (Advanced Supplementary) level information (i.e. age 18 educational variables): including the number of S, A and AS-levels in various categories (A-C and D-E for $\mathrm{S}$ and A-levels and A-C and D-G for AS-levels), obtained from the 30-year follow-up survey.

- O (Ordinary) levels, CSE (Certificate of Secondary Education), GCSE (General Certificate of Secondary Education) information (i.e. age 16 educational variables): including the number of O-levels, CSE and GCSE levels divided by grades (A-C, D-E for O-levels and GCSEs and 1, 2-5 for CSEs), obtained from the 30-year follow-up survey.

Including past educational variables may be important, since secondary school educational performance is likely to affect both the individual's demand for HE, i.e. the selection into educational qualifications, and wages. We note the possibility that there may be a recall bias associated with the use of past educational variables.

\footnotetext{
${ }^{15}$ The results of the F-tests are available upon request from the authors.
} 
All results are shown in Table 4. In the parsimonious specification the wage return to an UG degree is about 0.19 for men. Adding past educational variables (specification II) reduces the return to 0.14 . For men, the estimate of 0.19 is slightly higher that that reported in Table 2 for specification 3. However, as we have commented, specification 3 controls for employer characteristics whose effect is generally to reduce the coefficient on the educational qualifications. For women, the parsimonious specification, specification I, produces an estimate of the return to a degree of 0.23 the same as that reported under specification 3 in Table 2. Thus, for women, there is little impact from the inclusion of employer characteristics in the estimating equation. Specification II, however, produces an estimated return of 0.18. We conclude from our most preferred specification - that including additional secondary education variables - that the return for an undergraduate degree in the UK for the 1970 birth cohort was 0.14 for men and 0.18 for women.

We note that, in general, including past educational variables reduces the estimated return to a first degree. This comes as little surprise since individuals are likely to decide whether to continue in HE in part on the basis of their past educational performance. Moreover, HE institutions also select potential students on the basis of their pre-university educational performance. In both cases, therefore, we expect a positive correlation between secondary school performance variables and the highest educational qualification achieved, and accordingly a reduction in the return to a first degree. A surprising finding is that both HE dummies and past educational variables are statistically significant, representing therefore distinct sources of wage variation. However, this may be an artifact of the specific functional form chosen for the no-treatment outcome, in particular the constraint that the $X_{i}$ 's have the same effect on the outcome (log-wage) for both the treated and the non-treated. ${ }^{16}$ We will return to this issue in section 8 . It must be noted that, as with the HE qualification dummies, past educational qualifications may be affected by the same problems of endogeneity, i.e. correlation with individuals' unobserved earnings capacity, but this is the main reason

\footnotetext{
${ }^{16}$ For instance the effect of past educational variables on wages may be significant only for individuals with only A-level qualifications.
} 
why they are included in the log-wage regression following the proxy and matching approach.

\subsection{Differences by degree class}

In the previous section, we considered an undergraduate education to be a homogeneous commodity. However, students may be more or less successful in completing their UG studies. In particular, previous work has shown the positive effect of a 'good' degree performance on graduates' earnings. Battu et al. (1999) using data on two cohorts of graduates (from 1985 and 1990) found a positive log-wage premium of a first class honours degree with respect to upper and lower second class degrees (for females in 1985 and 1990 and males in 1990) for graduates' earnings one year after graduation. Furthermore, the degree premium associated with a 'first' turned out to be significant six years after graduation, for both males and females and for both cohorts of graduates. ${ }^{17}$

Similar evidence of an important role of degree class is also obtained by Naylor et al. (2003), using USR data for several cohorts of university leavers (from 1985/6 to 1993/4). The authors found, for instance, a significant positive premium, growing over time, associated with a first class degree on first destination occupational earnings of UK graduates. Neither the Battu et al. (1999) nor Naylor et al. (2003) papers are able to address the issue of returns to degrees relative to non-graduate outcomes as these studies are based on graduate data only, with no control group of non-graduates.

The BCS70 provides degree class for UG degrees, and here we are able to investigate differences in the return to an UG degree according to the class of degree awarded. In particular, in order to avoid small cell size problems we consider only two broad degree classes: 'good' degrees (first class or upper second class honour degrees) and lower degree classes. This distinction is also suggested by the common practice of some employers of conditioning job offers on the attainment of a 'good' degree result.

The estimation results are shown in Table $5 .{ }^{18}$ We base the analysis

\footnotetext{
${ }^{17}$ Battu et al. (1999) control for several individual characteristics which include the change of region, degree class, firm size, being self-employed and others.

${ }^{18}$ The sample size falls to 957 for men since 4 individuals did not report degree class.
} 
on specifications I and II from the previous section of the paper, replacing the dummy variable for obtaining an undergraduate degree with two dummy variables: one for obtaining a 'good' degree class and one for obtaining a lower degree class. For males, compared to an average return to an undergraduate degree of 0.19 (see Table 4) the estimated returns to a 'good' degree and lower degree classifications are 0.24 and 0.15 , respectively - when controls for past educational qualifications are not included - a difference which is significant at the $10 \%$ level. Adding past educational control variables again reduces the return to a 'good' degree to 0.19 and to 0.11 for a lower degree classification. An F-test for the equality of the return to different degree classes cannot now be rejected at conventional significance levels. Hence, our point estimates show a substantial distance between the log-wage premia to 'good' and to lower degree classifications, although the effects are not very precisely estimated, probably due to small cells size. Again, the change in the point estimates when including secondary school variables is in the direction we would have expected given the positive correlation between secondary school performance and performance in HE.

For females, compared to an average return to a first degree of 0.23 (see Table 4) the returns to a 'good' degree and a lower degree class are 0.26 and 0.18 , respectively, when past educational variables are not included - a difference which is significant at the $5 \%$ level. Inclusion of past educational variables reduces the size of the wage return to 'good' and a lower degree class to 0.21 and 0.14 , a difference which remains significant at the $10 \%$ level. Thus, our evidence tends to support findings by Battu et al. (1999) and Naylor et al. (2003) of variation in the returns to degrees according to the graduate's level of academic performance at university.

\subsection{Differences by degree subject}

In this section, we consider another possible source of heterogeneity in the return to UG degrees: the degree subject studied. Here, we are able to consider only broad aggregations of subjects studied because of the size of our sample. We focus on the following aggregation of subjects: Sciences (Medicine and Dentistry, Subjects Allied to Medicine, Biological Sciences, 
Agriculture, Physical Sciences, Mathematical Sciences, Computing, Engineering, Technology and Architecture), Social Sciences (Social Studies, Economics, Law and Politics, Business and Mass Communications), Art and Humanities (Classics and Literature, Modern European Languages, Other Languages, Creative Arts, Education and Other)

Table 6 shows our estimates. ${ }^{19}$ For men our estimated returns for the different subjects are not very different from those of Walker and Zhu (2001). Compared to an average return to a first degree of 0.19 estimated in Table 4 , Social Sciences have the highest wage return (0.26), and Art and Humanities the lowest wage return (0.12), which is not statistically different from zero at the $5 \%$ level. Adding controls for past educational variables reduces the estimated return to a first degree irrespective of subjects. However, their relative positions in terms of return do not change. F-tests for the equality of returns across all degree subjects cannot be rejected at the conventional statistical levels of significance. When we consider Social Sciences vs Art and Humanities, the difference is statistically significant at the $10 \%$ level.

For women, we observe the same ordering of subjects as for men, although the spread of the estimates around the average return of 0.23 estimated in Table 4 is much tighter, with Social Sciences having the highest wage return (0.25), and Art and Humanities the lowest return (0.18). When including secondary school variables the relative order of subjects remains unchanged, however the fall in the estimated returns is generally bigger than in the case of men. In neither case are the subject returns estimated precisely enough to render the differences statistically significant. However, as for males, the return to Social Sciences seems to be some distance apart from that of the other two subject groups. It is interesting to observe that unlike for men, women with a first degree in Art and Humanities earn significantly more than those with A-levels only, findings that are in line with Harkness and Machin (1999) and seem to suggest that women might self-select into Art and Humanities since they have comparative advantages with respect to men.

\footnotetext{
${ }^{19}$ The sample size falls to 930 for men and 996 for women since we dropped the individuals who did not report degree subject.
} 


\subsection{Differences by degree class and degree subject}

In this section we control both for degree class and degree subject, by allowing 'good' and lower degree classes to have different wage returns across subjects. This analysis is useful since the regressions including only degree subject or degree class may confound the effects of the two factors as in certain subjects 'good' degrees are relatively more frequent. However, when interacting degree subject and degree class we are likely to obtain even less precise estimates of the effects than in the previous sections given small cell sizes. In our estimation samples, for instance, the percentage of 'good' degrees is $47.44 \%$ in Sciences, $55.27 \%$ in Social sciences and $54.68 \%$ in Art and Humanities. Hence 'good' degrees are relatively less frequent in Sciences.

Table 7 shows the estimates for men. These estimates suggest that, for both 'good' and lower degree classes, wage returns to Social sciences degrees are relatively higher compared to those to the other degree subjects, confirming the results in section 6.3. The gap in returns between 'good' and lower degree classifications is high in Sciences where we have observed that the percentage of 'good' degrees is relatively lower, but also in Art and Humanities in which the percentage of 'good' degrees is comparatively higher. Therefore, in general there does not appear to be a monotonic relationship between the percentage of 'good' degrees awarded and the returns to 'good' degrees across subjects. The returns to 'good' and lower degrees in Social sciences is very similar, and this subject group can be classified as relatively riskless in terms of sensitivity of wage returns to degree performance. When controlling for secondary school performance in specification II the returns to all first degrees fall but the main conclusions do not change. The return to lower degree classes in Art and Humanities appears to be particularly low. As anticipated, small cell sizes generally do not allow the rejection of the null hypotheses of equality of returns between 'good' and lower degree classes within subjects and of 'good' degrees between subjects.

Table 8 shows the estimates for women. From specification I, probably the most interesting result is the strong similarity of the wage return to a 'good' degree across subjects. A 'good' degree performance appears to be an equally good investment no matter what subject female students studied 
and the null hypotheses of equality of returns to a 'good' degree by pairs of subjects are never rejected. The second result is the similarity of the returns to 'good' and lower degrees in Social sciences, which we have already observed for men. Therefore, as for men studying Social sciences appears to be a relatively riskless investment with respect to other subject groups, such as Sciences or Art and Humanities in which the gap in returns between 'good' and lower degree classifications is substantial. Also for women, including secondary school results leads to a fall in the estimated returns to all first degrees but the relative ordering in terms of returns does not change. The null hypotheses of equality of returns between 'good' and lower degree classes are rejected in all cases, although only marginally at the $10 \%$ level for Sciences, the subject in which the percentage of 'good' degrees is relatively lower: and therefore for which it is more likely that employers use a 'good' degree performance to screen among graduates.

\section{An alternative approach to endogeneity: the control function approach}

In the previous sections, we addressed the issue of potential endogeneity bias in estimating the return to a degree and used an approach based on a proxying and matching method. The idea underlying the proxying and matching method is to proxy the unobserved characteristics, which may cause endogeneity problems, with highly correlated observed characteristics. Although the BSC70 data set is very rich in information concerning family background, past education and ability-related variables, nothing really prevents the possibility that even after controlling for these characteristics there might still be some other omitted variables responsible for some residual correlation between the educational qualification dummies and the error term in the log-wage equation.

A possible alternative approach to the issue of endogeneity, associated with selection into educational qualifications through unobservables, is the control function approach (CFA hereafter, see Heckman and Robb, 1985). The CFA consists of simultaneously modelling both the process of educa- 
tional attainment and the process of generating wages. In particular, let us assume that educational qualifications are achieved according to the following process:

$$
\begin{aligned}
Q_{i 1} & =1\left(Q_{i j}^{*}<\mu_{1}\right) \\
Q_{i 2} & =1\left(\mu_{1} \leq Q_{i j}^{*}<\mu_{2}\right) \\
Q_{i 3} & =1\left(\mu_{2} \leq Q_{i j}^{*}<\mu_{3}\right) \\
Q_{i 4} & =1\left(Q_{i j}^{*} \geq \mu_{3}\right)
\end{aligned}
$$

with $Q_{i j}^{*}=B V_{i}+\nu_{i}$, where $Q_{i j}^{*}$ is a latent educational variable and $V_{i}$ some covariates affecting educational attainment, with $E\left(\nu_{i} \mid V_{i}\right)=0$. The $\mu_{j}$ 's are some parameters (thresholds) to be estimated.

If we assume that:

$$
\left(\nu_{i}, u_{i}\right) \sim N\left(\left(\begin{array}{l}
0 \\
0
\end{array}\right)\left(\begin{array}{ll}
1 & \rho \sigma \\
\rho \sigma & \sigma^{2}
\end{array}\right)\right)
$$

then it is straightforward to show that by including conditional mean terms or 'control functions' in equation (1) it is possible to obtain consistent estimates of the $b_{j}$ 's by running OLS on the following augmented regression:

$$
\begin{aligned}
\ln w_{i} & =m X_{i}+\sum_{j=2}^{J} b_{j} Q_{i j}+\sum_{j=1}^{J} E\left(u_{i} \mid Q_{i j}=1\right)+\omega_{i} \\
& =m X_{i}+\sum_{j=2}^{J} b_{j} Q_{i j}+\sum_{j=1}^{J} \rho \sigma \lambda_{i j} Q_{i j}+\omega_{i} \\
& =m X_{i}+\sum_{j=2}^{J} b_{j} Q_{i j}+\rho \sigma \sum_{j=1}^{J} \lambda_{i j} Q_{i j}+\omega_{i}
\end{aligned}
$$

where

$$
E\left(u_{i} \mid Q_{i j}=1\right)= \begin{cases}E\left(u_{i} \mid \nu_{i}<c_{1}\right)=\rho \sigma \frac{-\phi\left(c_{1}\right)}{\Phi\left(c_{1}\right)} \equiv \rho \sigma \lambda_{1 i} & \text { if } Q_{i 1}=1 \\ E\left(u_{i} \mid c_{1} \leq \nu_{i}<c_{2}\right)=\rho \sigma \frac{\phi\left(c_{1}\right)-\phi\left(c_{2}\right)}{\Phi\left(c_{2}\right)-\Phi\left(c_{1}\right)} \equiv \rho \sigma \lambda_{2 i} & \text { if } Q_{i 2}=1 \\ E\left(u_{i} \mid c_{2} \leq \nu_{i}<c_{3}\right)=\rho \sigma \frac{\phi\left(c_{2}\right)-\phi\left(c_{3}\right)}{\Phi\left(c_{3}\right)-\Phi\left(c_{2}\right)} \equiv \rho \sigma \lambda_{3 i} & \text { if } Q_{i 3}=1 \\ E\left(u_{i} \mid \nu_{i} \geq c_{3}\right)=\rho \sigma \frac{\phi\left(c_{3}\right)}{1-\Phi\left(c_{3}\right)} \equiv \rho \sigma \lambda_{4 i} & \text { if } Q_{i 4}=1\end{cases}
$$


and $c_{1 i}=\mu_{1}-B V_{i}, c_{2 i}=\mu_{2}-B V_{i}$ and $c_{3 i}=\mu_{3}-B V_{i}$ and $E\left(\omega_{i} \mid X_{i}, Q_{i j}, \lambda_{i}\right)=$ $0 .{ }^{20}$

Given the coefficient restriction on the artificial regressors $\lambda_{i j}$ 's, estimating equation (3) is equivalent to estimating the following:

$$
\ln w_{i}=m X_{i}+\sum_{j=2}^{J} b_{j} Q_{i j}+\rho \sigma \lambda_{i}+\omega_{i}
$$

where $\lambda_{i}=\sum_{j=1}^{J} \lambda_{i j} Q_{i j}$. Hence in equation (4) it is sufficient to include only one conditional mean term. The 'generalised residual' $\lambda_{i}$ is estimated from an ordered probit model of equation (2). Although the model is formally identified by the non-linearity of the education equation, it is usually thought that exclusion restrictions are necessary in order not to rely exclusively on functional form. Therefore, an 'economic' identification requires that at least one variable included in the education equation (i.e., in $V_{i}$ ) is excluded from the log-wage equation (i.e., from $X_{i}$ ).

In the following sections we use the CFA to estimate the log-wage premia to different educational qualifications and to different levels of degree performance.

We use as identifying variables some variables that were not significant in the log-wage equation estimated with OLS but that previous research has shown to be highly correlated with children's education: parents' educational qualifications (see Ermisch and Francesconi, 2001, and Chevalier and Lanot, 2002, among others). ${ }^{21}$ In particular, in the light of the fact the father's education turned out to be significant in women's wages, we use father's education for men and mother's education for women following therefore a 'gender role model' approach. Some recent evidence supporting

\footnotetext{
${ }^{20}$ See also Vella and Verbeek (1999) on how to model and estimate endogenous treatment effects.

${ }^{21}$ However, if education is endogenous the coefficients on the educational dummies as well as those on the other regressors, including the candidate 'instruments', will be affected by the 'endogeneity bias'. For this reason we replicate the test of significance of the instruments on the log-wage equation estimated with the CFA and without exclusion restrictions and report them in Table 10. Since the model using the CFA is identified without exclusion restrictions, through the functional form, the endogeneity problem is formally addressed and the coefficients on the 'instruments' are consistent.
} 
a stronger parents' effect on children's education for same-sex parents is provided by Chevalier (2004), for instance. For both men and women we use a parsimonious specification of the ordered probit model including only age 18 and age 16 educational variables and the identifying variables (father's highest educational qualification for men and mother's highest educational qualification for women).

The CFA offers a direct test for endogeneity (or self-selection through unobservables), which can also be interpreted as a specification test in the spirit of Heckman's (1979) seminal paper. In particular, the absence of endogeneity can be tested by testing whether the coefficient of the generalised residual (i.e. $\rho \sigma$ ) equals zero. Implicitly, what the test says is whether the omitted variables in the log-wage equation, entering $u_{i}$, and in the education equation, entering $\nu_{i}$, are correlated or not, and therefore whether or not the educational qualifications dummies are correlated with $u_{i}$. If they are not correlated the log-wage equation (1) should be estimated using OLS, otherwise OLS should be applied on equation (4). Thus the t-test on the coefficient of the generalised residual can also be interpreted as a test for the omission of variables correlated with educational qualifications from the log-wage equation, i.e. as a test for omitted variables.

Table 9 shows the estimation results from the CFA for both males and females. In the light of the significance of the past educational qualifications on the log-wage shown in tables 4 and 5, we estimate only specification II, including both age 18 and age 16 educational variables. Table 9 reports the results of F-tests for the significance of the identifying variables. Our 'instruments' do not appear to be 'weak': ${ }^{22}$ parents' educational qualifications are generally highly significant in the selection equation (the ordered probit) but not in the log-wage equation. In all cases the coefficient of the generalised residual is not significant, showing the absence of an endogeneity problem. ${ }^{23}$

\footnotetext{
${ }^{22}$ Such a test is suggested in Bound et al. (1995).

${ }^{23}$ Apart from the lack of statistical significance of the coefficient on the generalised residual, which might be not very precisely estimated, it is important to note that the estimates of the wage returns using the CFA approach are very close to those obtained from the proxying and matching method.
} 
We use the same framework (i.e. two-stage estimation of the log-wage equation with a selection equation estimated through an ordered probit) to test the potential endogeneity of degree class. In particular, the generalised residual is estimated using an ordered probit with five categories (in increasing order: A-level, Non-degree HE, 'lower degree' class, 'good' degree, PG degree). Table 10 reports the results. We use the same identifying variables employed to address the endogeneity of the educational qualifications, and find them to be generally valid, as the F-tests suggest. As we also saw for the educational qualifications, there is no evidence of an endogeneity problem: the coefficient of the generalised residual is never statistically significant.

Unfortunately, our data are not sufficiently rich to permit convincing tests for the potential endogeneity of degree subjects, along the lines suggested by Lee (1983). We would need variables affecting subject choice but not wages. Parents' education appears to be a much less appropriate instrument for the choice of degree subject than for the level of education or degree performance. Moreover, past educational variables, which are likely to affect the type of subject chosen appear to have a significant impact also on wages and therefore are not suitable instruments.

Hence, we cannot exclude the possibility that our estimates of degree subject returns may be affected by a selection bias. However, we do conclude that there is no evidence of ability bias in the estimation of either the return to educational qualifications or to degree class. Individuals do not seem to self-select into educational qualifications according to their earnings capacity; in other words, individuals who expect to earn more do not necessarily acquire more education or have a better degree performance.

\section{The case of heterogeneous returns}

Our previous analysis suggests the absence of an ability bias both in the estimation of the returns to a degree and in that for returns by class of degree. However, as in the case of selection exclusively on observables, OLS estimates will recover the unbiased ATT only if the no-treatment outcome has been correctly specified (i.e. the model is correctly specified in terms of the covariates included and the functional form chosen) and if the treatment ef- 
fect is homogeneous across individuals with different observed characteristics (i.e. treatment has only an intercept and not a slope effect). A method that allows us to relax these assumptions is the estimation of Average Treatment Effects on the Treated based on propensity score matching. A description of the method can be found in Becker and Ichino (2002). In this section we estimate the return to a first degree using propensity score matching.

Let us define $X_{i}$ as a vector of variables affecting both educational qualifications and wages, $Q_{i}$ the treatment variable that equals one for the treated and zero for the non-treated (in our case it will be the dummy for having a first degree) and $w_{1 i}$ and $w_{0 i}$ the log-wage for individual $i$ in the case of treatment and no-treatment, respectively. Following Rosenbaum and Rubin (1983) the propensity score is defined as:

$$
p\left(X_{i}\right) \equiv \operatorname{Pr}\left\{Q_{i}=1 \mid X_{i}\right\}=E\left\{Q_{i} \mid X_{i}\right\}
$$

i.e. the conditional probability of receiving a treatment given pre-treatment characteristics. Rosenbaum and Rubin (1983) show that if the following two hypotheses hold:

1. Balancing hypothesis: If $p\left(X_{i}\right)$ is the propensity score, then $Q_{i} \perp$ $X_{i} \mid p\left(X_{i}\right)$;

2. Unconfoundedness hypothesis: Suppose that assignment to treatment is unconfounded, ${ }^{24}$ i.e. $w_{1 i}, w_{0 i} \perp Q_{i} \mid X_{i}$. Then assignment to treatment is unconfounded given the propensity score, i.e. $w_{1 i}, w_{0 i} \perp$ $Q_{i} \mid p\left(X_{i}\right)$;

then the Average Treatment effect on the Treated (ATT) can be estimated as follows:

$$
\begin{aligned}
A T T & =E\left\{w_{1 i}-w_{0 i} \mid Q_{i}=1\right\} \\
& =E\left\{E\left\{w_{1 i}-w_{0 i} \mid Q_{i}=1, p\left(X_{i}\right)\right\}\right\} \\
& =E\left\{E\left\{w_{1 i} \mid Q_{i}=1, p\left(X_{i}\right)\right\}-E\left\{w_{0 i} \mid Q_{i}=0, p\left(X_{i}\right)\right\} \mid Q_{i}=1\right\} .
\end{aligned}
$$

\footnotetext{
${ }^{24}$ This hypothesis is also called the Conditional Independence Assumption, i.e. selection only on observables, and cannot be tested within the propensity score-ATT framework.
} 
In our case, propensity score matching and ATT are implemented using the procedures pscore and attnd created by Becker and Ichino (2002), the latter using as options Nearest Neighbour Matching with replacement and a probit model to compute propensity scores. The procedure pscore also offers some diagnostics for the balancing property. Both for males and females, the balancing property was satisfied for all variables used for the computation of the propensity score. Standard errors for the ATT were computed using bootstrap and 500 replications. Table 11 reports the OLS estimates of the return to a first degree using specification II in section 4 for the computation of the propensity scores, on the common support sample, in order to assess the impact of the potential lack of common support. For males the ATT computed is 0.12 , not statistically significant at the conventional levels and lower than that computed in section 6.1 using OLS. Lack of common support does not seem to be a problem, since more than $99 \%$ of observations fall in the common support. ${ }^{25}$ The OLS estimates in the common support are very similar to the ATT computed using propensity score matching showing that for males a linear specification of the no-treatment outcome and the hypothesis of homogeneity of treatment effects are reasonable assumptions. The estimated effect is slightly lower than that reported in section 6.1. The difference is probably due to the fact that here we are considering only the sample of individuals with A-levels or a first degree, i.e. the two groups of individuals who are more directly comparable (see section 3 ). This suggests the need for a careful choice of the control group when assessing the impact of the treatment outcome in order to ensure that the treated and control groups are as similar as possible. Furthermore, for women, the lack of common support also appears not to be a problem, and again the estimated effect is lower than that in section 6.1. For females the estimated effect from the PSM-ATT procedure is 0.15 , statistically significant at $5 \%$.

\footnotetext{
${ }^{25}$ This is the percentage of observations whose propensity score belongs to the intersection of the supports of the propensity score of treated and control observations. The problem of 'lack of common support' arises when the intersection of the two supports, of the treated and untreated groups, is very small, suggesting that treated and untreated individuals have very different observed characteristics and are not easily comparable.
} 


\section{Concluding remarks}

In this paper we have estimated the return to a first degree using data from the 1970 British birth cohort (BCS70). In order to tackle the issue of potential endogeneity of educational qualifications we have used the proxying and matching method that consists of including in the log-wage equation factors affecting both educational attainment and wages. This approach may be a viable solution to the possible endogeneity problem given that the data set used is very rich in information related to family background, ability related variables and past educational performance. We have replicated the NCDS 1958 birth cohort analysis of Blundell et al. (2000) on BCS70 data and have shown that while the return to a first degree is largely unchanged for men belonging to the 1958 and the 1970 cohorts, the return for women has declined substantially over the two cohorts. From a specification which attempts to replicate that of Blundell et al. (2000), we estimate the wage return to be 0.15 for men and 0.23 for women in the 1970 cohort compared to 0.17 and 0.37 , respectively, for the 1958 cohort. Our own preferred specifications for the 1970 cohort leads to an estimated return to a degree of 0.14 for men and 0.18 for women.

We have also analysed differences in returns according to both degree class and degree subjects. Our estimates show the existence of a positive additional log-wage premium for 'good' degrees compared to lower degree classifications. For both men and women, the premium for a 'good' degree over a poor degree is about 8 percentage points. However, our estimates are not very precise, probably because of relatively small cell sizes, and in our samples the hypothesis of no difference between degree classes can be rejected at the $5 \%$ level only for women. Our results qualitatively confirm previous findings by Battu et al. (1999) and Naylor et al. (2003) who also found earnings premia for a 'good' degree performance, using larger samples where the effects can be more precisely estimated, albeit without information on a non-graduate control group. Our analysis of log-wage differences by degree subjects also confirms findings from related work. As far as the ranking of subjects is concerned, for instance, we have in decreasing order: Social Sciences, Sciences and Art and Humanities, both for men and women. 
Moreover, Art and Humanities degrees give a positive return (relative to workers with A-levels) only in the case of women. Although our estimates suggest the presence of differences by degree subjects, the effects are not always precisely estimated and only the difference between Social Sciences and Art and Humanities degrees appears statistically significant for males. In one of our reported estimations, we considered the interaction between degree subject and degree class. We find that this does not affect the ranking of subjects, though we notice that the return to a 'good' degree relative to a lower class degree is quantitatively greater for Science than for Social Science subjects. This is consistent with a relatively lower proportion of 'good' degrees awarded in Science rendering those awarded relatively more valuable.

We have also tested for the presence of endogeneity in our estimates of the return to a first degree and to degree class using the control function approach. In both cases the hypothesis of an absence of endogeneity could not be rejected by our data. This is perhaps not a very surprising result since in the present paper we consider a sample of individuals who have attained at least an A-level education. Once we have controlled for several family and individual characteristics including early academic ability, this sample is likely to be relatively homogeneous with respect to unobserved characteristics.

Finally, we have explored the issue of the heterogeneity of returns to a first degree by observed household and individual characteristics, other than degree class and degree subject, and the adequacy of the linear specification using a Propensity Score Matching-Average Treatment Effect approach. Our results suggest that when estimating the return to a first degree and considering as the control group individuals with A-levels only, the absence of common support is not an issue and that the assumptions of the linear specification and the homogeneity of treatment effects do not seem to be too strong in our sample.

In conclusion, our estimates suggest that for males, the return to a university degree in the UK is remarkably similar across the 1970 birth cohort typically graduating in the early 1990s - and the 1958 birth cohort, typically graduating in 1979 or 1980 . This is despite the significant changes taking 
place in UK HE during the 1980s. In contrast, our estimates suggest that the return to a degree for females fell considerably across the two cohorts.

\section{References}

Battu, H., Belfield, C. and Sloane, P. (1999), "Overeducation among graduates: A cohort view", Education Economics, 7: 21-38.

Becker, S. and Ichino, A., (2002), "Estimation of average treatment effects based on propensity scores", The Stata Journal, 2: 358-377.

Belfield, C., Bullock, A., Chevalier, A., Fielding, A., Siebert, W. S. and Thomas, H. (1997), Mapping the careers of highly qualified workers. Bristol: Higher Education Funding Council for England.

Betts, J. R. (1996), "What do students know about wages? Evidence from a survey of undergraduates", Journal of Human Resources, 31: 27-56.

Blundell. R., Dearden, L., Goodman, A. and Reed, H. (2000), "The returns to higher education in Britain: Evidence from a British cohort", Economic Journal, 110: F82-F89.

Blundell, R., Dearden, L. and Sianesi, B. (2003), "Evaluating the impact of education on earnings in the UK: Models, methods and results from the NCDS", IFS Working Paper no. 03/20, The Institute for Fiscal Studies, London.

Bound, J., Jaeger, D.A., and Baker, R.M. (1995), "Problems with instrumental variable estimation when the correlation between the instruments and the endogenous explanatory variable is weak", Journal of the American Statistical Association, 90: 443-450.

Card, D. (1999), "The causal effect of education on earnings" in O. Ashenfelter and D. Card (eds), Handbook of Labor Economics, Volume 3A, 1801-1863. Amsterdam: Elsevier.

Chevalier, A. (2003), "Measuring over-education', Economica, 70: 509-531.

Chevalier, A. (2004), "Parental education and child's education: A natural experiment", IZA Discussion Paper no. 1153, IZA, Bonn. 
Chevalier, A. and Conlon, G. (2003), "Does it pay to attend a prestigious university?', IZA Discussion Paper no. 848, IZA, Bonn.

Chevalier, A., Conlon, G., Galindo-Rueda, F. and McNally, S. (2002), "The returns to higher education teaching", Research Report to the Department for Education and Skills (DfES), Center for the Economics of Education, London.

Chevalier, A. and Lanot, G. (2002), "The relative effect of family characteristics and financial situation on educational achievement", Education Economics, 10: $165-182$.

Chevalier, A., Harmon., C., Walker, I. and Zhu, Y. (2004), "Does education raise productivity, or just reflect it?", Economic Journal, 114: F499F517.

Dearden, L. (1999), "Qualifications and earnings in Britain: How reliable are conventional OLS estimates of the returns to education?" IFS Working Paper no. 99/7, The Institute for Fiscal Studies, London.

Dolton, P., and Makepeace, G. H. (1990). "The earnings of economics graduates", Economic Journal, 100: 237-250.

Dolton P., Makepeace, G. and Inchley, G. D. (1990), "The early careers of 1980 graduates: Earnings, earnings differentials and postgraduate study", Employment Department Group Research Paper no.78, London: HMSO.

Dolton, P., and Vignoles, A. (2000) "The incidence and effects of overeducation in the UK graduate labour market", Economics of Education Review, 19: 179-98.

Dominitz, J., and Manski, C. F. (1996), "Eliciting student expectations of the returns to schooling", Journal of Human Resources, 31: 1-26.

Elliot, C. D., Murray, D. J. and Pearson, L. S. (1979), British ability scales, manual 4: Tables of abilities and norms. Windsor: NFER.

Ermisch, J. and Francesconi, M. (2001), "Family matters: Impacts of family background on educational attainments", Economica, 68: 137-156.

Goos, M. and Manning, A. (2003), "Lousy and lovely jobs: the rising polarization of work in Britain", CEP Discussion Paper no. 604, London School of Economics, December 2003. 
Green, F., McIntosh, S. and Vignoles, A. (1999), "Overeducation and skills clarifying the concepts", CEP Discussion Paper no. 453, London

Greenaway, D. and Haynes, M. (2003) "Funding higher education in the UK: The role of fees and loans", Economic Journal, 113: F150-F166.

Hartog, J. (2000), "Over-education and earnings: Where are we, where should we go?", Economics of Education Review, 19: 131-147

Harkness, S. and Machin, S. (1999), "Graduate earnings in Britain, 1974-95", Department for Education and Employment, Research Report RR95.

Harkness, S. (2004), "Pay Inequality: Gender", mimeo, University of Bristol.

Heckman, J. J., (1979), "Sample selection bias as a specification error", Econometrica, 47: 153-161.

Heckman, J., Lochner, L., and Todd, P. (2003), "Fifty years of Mincer earnings regressions", IZA Discussion Paper, no. 775, Bonn.

Heckman, J. and Robb, R. (1985), "Alternative identifying assumptions in econometric models of selection bias", Advances in Econometrics, 5: 243-287.

Kane, T., Rouse, C.E. and Staiger, D. (1999), "Estimating the returns to schooling when schooling is misreported", National Bureau of Economic Research, Working Paper no. 7235. Cambridge, MA: NBER.

Lee, L.-F. (1983), "Generalized econometric models with selectivity", Econometrica, 51: 507-512.

Lissenburgh, S. and Bryson, A. (1996), "The returns to graduation", Research Studies RS15, Department for Education and Employment Norwich: DfEE.

Makepeace, G., Paci, P., Joshi, H., Dolton, P. (1999), "How Unequally Has Equal Pay Progressed Since the 1970s? A Study of Two British Cohorts", Journal of Human Resouces, 34: 534-556.

Mason, G. (1995), "The new graduate supply-shock. Recruitment and utilisation of graduates in British industry", National Institute of Economic Research, Report Series no. 9, London.

Naylor, R. and Smith, J. (2004), "Returns to education: A signaling approach", mimeo, University of Warwick, Coventry. 
Naylor, R., Smith, J. and McKnight, A. (2003), "Returns to educational performance: Evidence from UK graduates' first destination labour market outcomes", mimeo, University of Warwick, Coventry.

Pereira, P. T. and Martins, P. S. (2004), "Returns to education and wage equations", Applied Economics, 36: 525-531.

Rigg, M., Elias, P., White, M. and Johnson, S. (1990), An Overview of the Demand for Graduates, HMSO, London.

Rosenbaum, P. and Rubin, D.B. (1983), "The central role of the propensity score in observational studies for causal effects", Biometrika, 70: 41-55.

Sloane, P.J. and O'Leary, N.C. (2005), "The changing wage return to an undergraduate education", IZA Discussion Paper no. 1549, IZA, Bonn.

Vella, F. and Verbeek, M. (1999), "Estimating and interpreting models with endogenous treatment effects", Journal of Business and Economic Statistics, 17: 473-478.

Walker, I. and Zhu, Y. (2001), "The returns to education: evidence for the labour force survey", Department for Education and Skills Research Paper no. 313. Norwich: DfES.

Wolter, S. C. and Zbinden, A. (2002), "Labour market expectations of Swiss university students", International Journal of Manpower, 23: 458-470. 


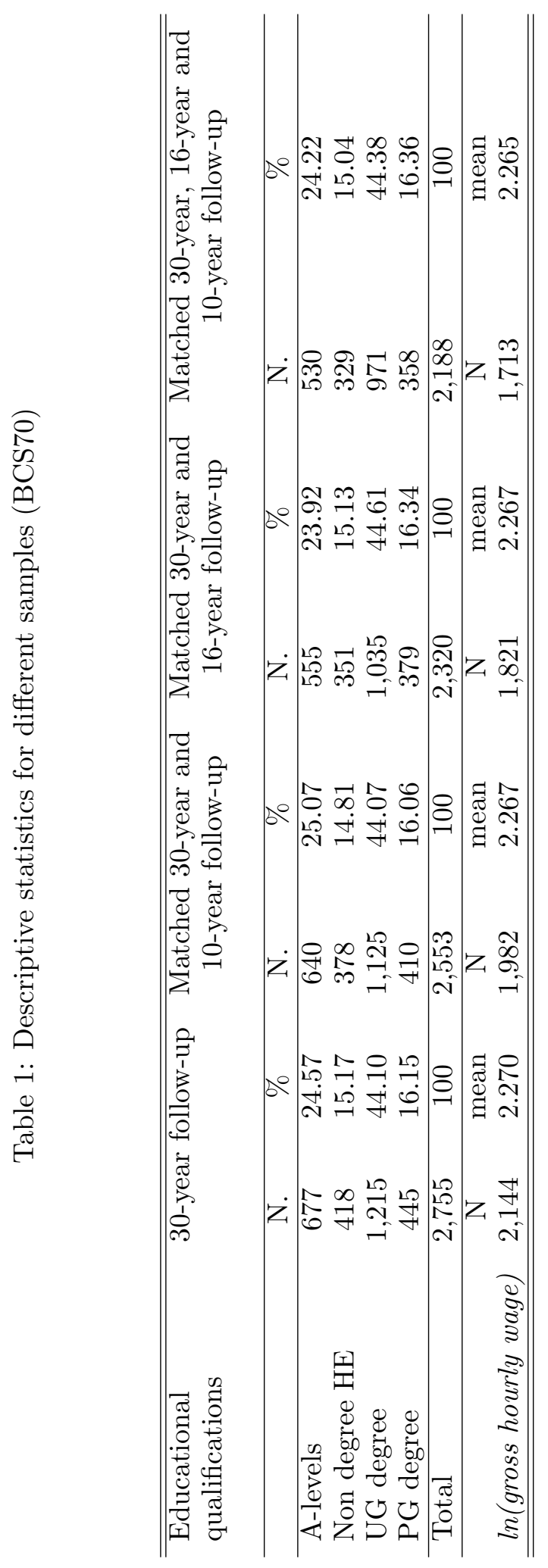




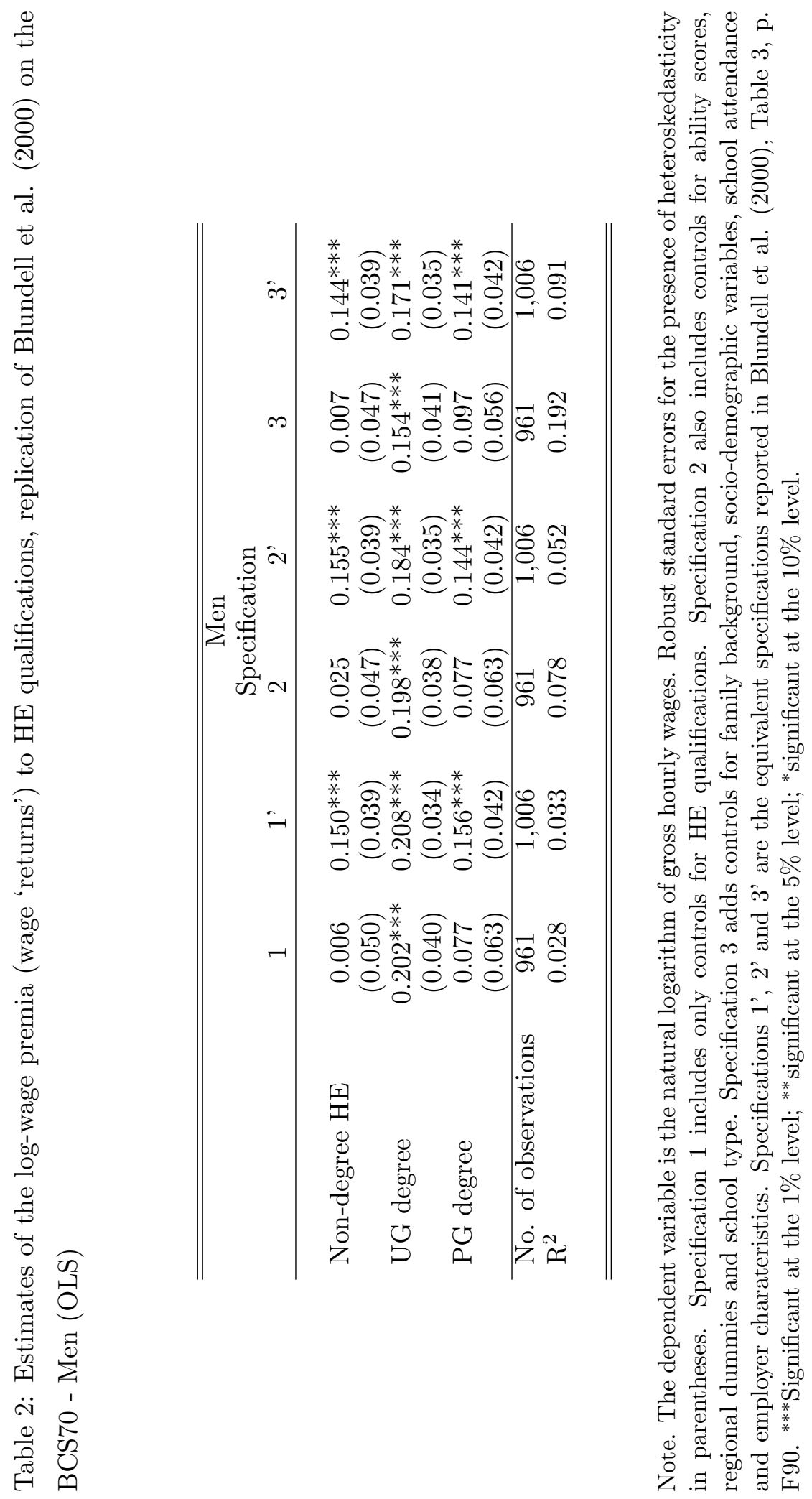




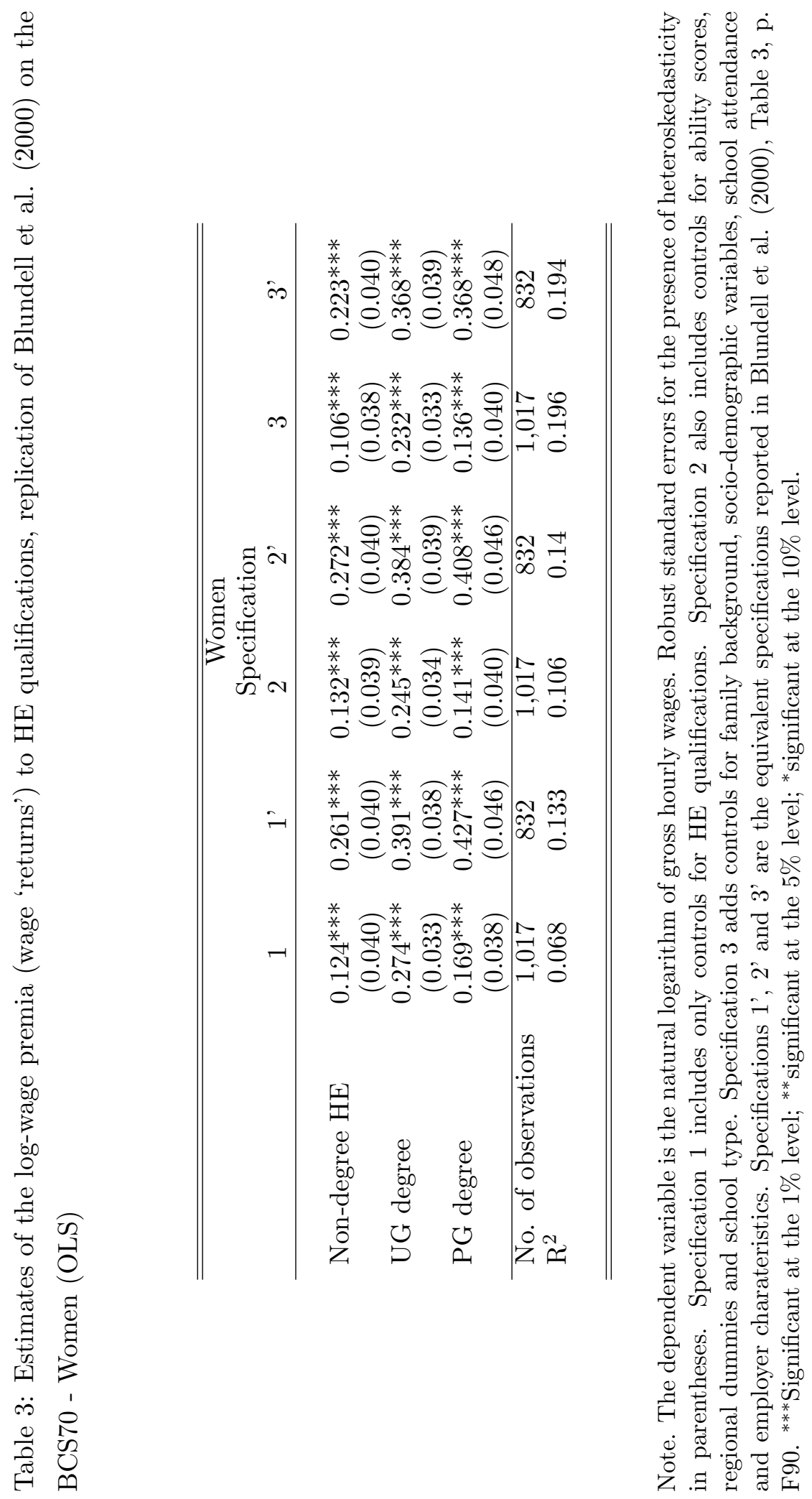


Table 4: Estimates of the log-wage premia (wage 'returns') to a first degree (BCS70) - OLS

\begin{tabular}{|c|c|c|c|c|c|c|}
\hline \multirow{3}{*}{$\begin{array}{l}\text { Return to } \\
\text { UG degree }\end{array}$} & \multicolumn{6}{|c|}{ Specification } \\
\hline & & I & & & II & \\
\hline & Coef. & & s.e. & Coef. & & s.e. \\
\hline \multicolumn{7}{|l|}{ Men } \\
\hline UG degree & 0.189 & $* * *$ & 0.039 & 0.142 & $* * *$ & 0.042 \\
\hline F-test A-level info. (p-value) & & - & & & 0.004 & \\
\hline F-test O-level info. (p-value) & & - & & & 0.003 & \\
\hline N.obs. & & 961 & & & 961 & \\
\hline $\mathrm{R}^{2}$ & & 0.092 & & & 0.125 & \\
\hline \multicolumn{7}{|l|}{ Women } \\
\hline UG degree & 0.229 & $* * *$ & 0.033 & 0.180 & **** & 0.035 \\
\hline F-test A-level info. (p-value) & & - & & & 0.056 & \\
\hline F-test O-level info. (p-value) & & - & & & 0.009 & \\
\hline N.obs. & & 1,017 & & & 1,017 & \\
\hline $\mathrm{R}^{2}$ & & 0.133 & & & 0.165 & \\
\hline
\end{tabular}

Note. The dependent variable is the natural logarithm of gross hourly wages. Specifications I also includes for men: region of residence, British ability scales scores (both quantitative and non quantitative), school type and father's social class. Specification I includes for women: region of residence, British ability scales scores (both quantitative and non quantitative), school type and father's education. Specification II includes all the controls of specification I and controls for age 16 and age 18 secondary school performance. The regressors included in specification I were chosen by performing F-tests on the general specification including all controls listed in section 6.1. Robust standard errors for the presence of heteroskedasticity in parentheses. ${ }^{* * *}$ Significant at the $1 \%$ level; ${ }^{* *}$ significant at the $5 \%$ level; ${ }^{*}$ significant at the $10 \%$ level. 
Table 5: Estimates of the log-wage premia (wage 'returns') by degree class (BCS70) - OLS

\begin{tabular}{|c|c|c|c|c|c|c|}
\hline \multirow{3}{*}{$\begin{array}{l}\text { Return to } \\
\text { UG degree class }\end{array}$} & \multicolumn{6}{|c|}{ Specification } \\
\hline & & I & & & II & \\
\hline & Coef. & & s.e. & Coef. & & s.e. \\
\hline \multicolumn{7}{|l|}{ Men } \\
\hline 'Good' degree & 0.239 & $* * *$ & 0.050 & 0.187 & $* * *$ & 0.051 \\
\hline Lower degree class & 0.153 & $* * *$ & 0.044 & 0.112 & $* *$ & 0.047 \\
\hline F-test A-level info. (p-value) & & - & & & 0.004 & \\
\hline F-test O-level info. (p-value) & & - & & & 0.005 & \\
\hline F-test good=other $(p$-value $)$ & & 0.101 & & & 0.145 & \\
\hline N.obs & & 957 & & & 957 & \\
\hline $\mathrm{R} \$^{2}$ & & 0.095 & & & 0.127 & \\
\hline \multicolumn{7}{|l|}{ Women } \\
\hline 'Good' degree & 0.262 & *** & 0.037 & 0.211 & $* * *$ & 0.038 \\
\hline Lower degree class & 0.183 & $* * *$ & 0.041 & 0.142 & **** & 0.041 \\
\hline F-test A-level info. (p-value) & & - & & & 0.061 & \\
\hline F-test O-level info. (p-value) & & - & & & 0.010 & \\
\hline F-test good=other (p-value) & & 0.046 & & & 0.071 & \\
\hline N.obs & & 1,017 & & & 1,017 & \\
\hline $\mathrm{R}^{2}$ & & 0.137 & & & 0.168 & \\
\hline
\end{tabular}

Note. The dependent variable is the natural logarithm of gross hourly wages. Specifications I also includes for men: region of residence, British ability scales scores (both quantitative and non quantitative), school type and father's social class. Specification I includes for women: region of residence, British ability scales scores (both quantitative and non quantitative), school type and father's education. Specification II includes all the controls of specification I and controls for age 16 and age 18 secondary school performance. The regressors included in specification I were chosen by performing F-tests on the general specification including all controls listed in section 6.1. Robust standard errors for the presence of heteroskedasticity in parentheses. ${ }^{* * *}$ Significant at the $1 \%$ level; ${ }^{* *}$ significant at the $5 \%$ level; ${ }^{*}$ significant at the $10 \%$ level. 
Table 6: Estimates of the log-wage premia (wage 'returns') by degree subject (BCS70)- OLS

\begin{tabular}{|c|c|c|c|c|c|c|}
\hline \multirow{3}{*}{$\begin{array}{l}\text { Return to } \\
\text { UG degree subject }\end{array}$} & \multicolumn{6}{|c|}{ Specification } \\
\hline & \multicolumn{3}{|c|}{ I } & \multicolumn{3}{|c|}{ II } \\
\hline & Coef. & & s.e. & Coef. & & s.e. \\
\hline \multicolumn{7}{|l|}{ Men } \\
\hline Sciences (S) & 0.192 & $* * *$ & 0.046 & 0.131 & *** & 0.050 \\
\hline Social sciences (SS) & 0.259 & $* * *$ & 0.059 & 0.212 & $* * *$ & 0.060 \\
\hline Art and humanities (AH) & 0.117 & $*$ & 0.066 & 0.082 & & 0.065 \\
\hline F-test A-level info. (p-value) & & - & & & 0.004 & \\
\hline F-test O-level info. (p-value) & & - & & & 0.005 & \\
\hline F-test $\mathrm{S}=\mathrm{SS}(\mathrm{p}$-value $)$ & & 0.272 & & & 0.179 & \\
\hline F-test $\mathrm{S}=\mathrm{AH}$ (p-value) & & 0.269 & & & 0.449 & \\
\hline F-test SS = AH (p-value $)$ & & 0.067 & & & 0.084 & \\
\hline F-test all subjects $=(p$-value $)$ & & 0.184 & & & 0.205 & \\
\hline N.obs & & 930 & & & 930 & \\
\hline $\mathrm{R}^{2}$ & & 0.099 & & & 0.132 & \\
\hline \multicolumn{7}{|l|}{ Women } \\
\hline Sciences (S) & 0.208 & $* * *$ & 0.039 & 0.136 & $* * *$ & 0.040 \\
\hline Social sciences (SS) & 0.246 & $* * *$ & 0.052 & 0.185 & $* * *$ & 0.053 \\
\hline Art and humanities (AH) & 0.181 & $* * *$ & 0.043 & 0.121 & $* * *$ & 0.043 \\
\hline F-test A-level info. (p-value) & & - & & & 0.018 & \\
\hline F-test O-level info. (p-value) & & - & & & 0.005 & \\
\hline F-test $S=S S(p$-value) & & 0.456 & & & 0.343 & \\
\hline F-test $\mathrm{S}=\mathrm{AH}(\mathrm{p}$-value $)$ & & 0.536 & & & 0.231 & \\
\hline F-test $\mathrm{SS}=\mathrm{AH}(\mathrm{p}$-value $)$ & & 0.221 & & & 0.724 & \\
\hline F-test all subjects $=(\mathrm{p}$-value $)$ & & 0.472 & & & 0.479 & \\
\hline N.obs & & 996 & & & 996 & \\
\hline $\mathrm{R}^{2}$ & & 0.136 & & & 0.174 & \\
\hline
\end{tabular}

Note. The dependent variable is the natural logarithm of gross hourly wages. Specifications I also includes for men: region of residence, British ability scales scores (both quantitative and non quantitative), school type and father's social class. Specification I includes for women: region of residence, British ability scales scores (both quantitative and non quantitative), school type and father's education. Specification II includes all the controls of specification I and controls for age 16 and age 18 secondary school performance. The regressors included in specification I were chosen by performing $\mathrm{F}$-tests on the general specification including all controls listed in section 6.1. Robust standard errors for the presence of heteroskedasticity in parentheses. ${ }^{* * *}$ Significant at the $1 \%$ level; ${ }^{* *}$ significant at the $5 \%$ level; ${ }^{*}$ significant at the $10 \%$ level. 
Table 7: Estimates of the log-wage premia (wage 'returns') by degree subject and degree class for men (BCS70) - OLS

\begin{tabular}{|c|c|c|c|c|c|c|}
\hline \multirow{3}{*}{$\begin{array}{l}\text { Return to } \\
\text { UG degree class } \\
\text { by subject }\end{array}$} & \multicolumn{6}{|c|}{ Specification } \\
\hline & \multirow[b]{2}{*}{ Coef. } & \multirow[t]{2}{*}{ I } & \multirow[b]{2}{*}{ s.e. } & \multirow[b]{2}{*}{ Coef. } & \multirow[t]{2}{*}{ II } & \multirow[b]{2}{*}{ s.e. } \\
\hline & & & & & & \\
\hline \multicolumn{7}{|l|}{ Men } \\
\hline Sciences $(S)$ & & & & & & \\
\hline 'Good' degree & 0.231 & $* * *$ & 0.071 & 0.174 & $* *$ & 0.071 \\
\hline Lower degree class & 0.167 & $* * *$ & 0.050 & 0.104 & $*$ & 0.054 \\
\hline \multicolumn{7}{|l|}{ Social sciences (SS) } \\
\hline 'Good' degree & 0.288 & $* * *$ & 0.070 & 0.238 & $* * *$ & 0.071 \\
\hline Lower degree class & 0.222 & $* *$ & 0.088 & 0.185 & $* *$ & 0.089 \\
\hline \multicolumn{7}{|l|}{ Art and humanities (AH) } \\
\hline 'Good' degree & 0.159 & $*$ & 0.081 & 0.107 & & 0.080 \\
\hline Lower degree class & 0.073 & & 0.065 & 0.028 & & 0.097 \\
\hline F-test 'good' S=lower S (p-value) & & 0.392 & & & 0.354 & \\
\hline F-test 'good' SS=lower SS (p-value) & & 0.525 & & & 0.609 & \\
\hline F-test 'good' $\mathrm{AH}=$ lower $\mathrm{AH}$ (p-value) & & 0.436 & & & 0.504 & \\
\hline F-test 'good' $S=$ lower SS (p-value) & & 0.530 & & & 0.473 & \\
\hline F-test 'good' $\mathrm{SS}=$ lower AH (p-value) & & 0.190 & & & 0.175 & \\
\hline F-test 'good' S=lower AH (p-value) & & 0.468 & & & 0.490 & \\
\hline N.obs & & 928 & & & 928 & \\
\hline & & 0.100 & & & 0.118 & \\
\hline
\end{tabular}

Note. The dependent variable is the natural logarithm of gross hourly wages. Specifications I also includes for men: region of residence, British ability scales scores (both quantitative and non quantitative), school type and father's social class. Specification I includes for women: region of residence, British ability scales scores (both quantitative and non quantitative), school type and father's education. Specification II includes all the controls of specification I and controls for age 16 and age 18 secondary school performance. The regressors included in specification I were chosen by performing F-tests on the general specification including all controls listed in section 6.1. Robust standard errors for the presence of heteroskedasticity in parentheses. ${ }^{* * *}$ Significant at the $1 \%$ level; ${ }^{* *}$ significant at the $5 \%$ level; ${ }^{*}$ significant at the $10 \%$ level. 
Table 8: Estimates of the log-wage premia (wage 'returns') by degree subject and degree class for women (BCS70) - OLS

\begin{tabular}{|c|c|c|c|c|c|c|}
\hline \multirow{3}{*}{$\begin{array}{l}\text { Return to } \\
\text { UG degree class } \\
\text { by subject }\end{array}$} & \multicolumn{6}{|c|}{ Specification } \\
\hline & \multirow[b]{2}{*}{ Coef. } & \multirow[t]{2}{*}{ I } & \multirow[b]{2}{*}{ s.e. } & \multirow[b]{2}{*}{ Coef. } & \multirow[t]{2}{*}{ II } & \multirow[b]{2}{*}{ s.e. } \\
\hline & & & & & & \\
\hline \multicolumn{7}{|l|}{ Women } \\
\hline Sciences (S) & & & & & & \\
\hline 'Good' degree & 0.242 & $* * *$ & 0.047 & 0.181 & $* * *$ & 0.046 \\
\hline Lower degree class & 0.155 & $* * *$ & 0.049 & 0.092 & $*$ & 0.052 \\
\hline \multicolumn{7}{|l|}{ Social sciences (SS) } \\
\hline 'Good' degree ' & 0.266 & $* * *$ & 0.057 & 0.202 & $* * *$ & 0.058 \\
\hline Lower degree class & 0.224 & $* * *$ & 0.080 & 0.184 & $* *$ & 0.079 \\
\hline \multicolumn{7}{|l|}{ Art and humanities (AH) } \\
\hline 'Good' degree & 0.222 & $* * *$ & 0.055 & 0.166 & $* * *$ & 0.055 \\
\hline Lower degree class & 0.129 & $* *$ & 0.054 & 0.082 & & 0.055 \\
\hline F-test 'good' $\mathrm{S}=$ lower S (p-value) & & 0.121 & & & 0.104 & \\
\hline F-test 'good' SS=lower SS (p-value) & & 0.638 & & & 0.846 & \\
\hline F-test 'good' AH=lower AH (p-value) & & 0.162 & & & 0.208 & \\
\hline F-test 'good' $S=$ lower SS (p-value) & & 0.702 & & & 0.742 & \\
\hline F-test 'good' SS=lower AH (p-value) & & 0.530 & & & 0.602 & \\
\hline F-test 'good' S=lower AH (p-value)' & & 0.747 & & & 0.793 & \\
\hline N.obs & & 996 & & & 996 & \\
\hline & & 0.140 & & & 0.159 & \\
\hline
\end{tabular}

Note. The dependent variable is the natural logarithm of gross hourly wages. Specifications I also includes for men: region of residence, British ability scales scores (both quantitative and non quantitative), school type and father's social class. Specification I includes for women: region of residence, British ability scales scores (both quantitative and non quantitative), school type and father's education. Specification II includes all the controls of specification I and controls for age 16 and age 18 secondary school performance. The regressors included in specification I were chosen by performing F-tests on the general specification including all controls listed in section 6.1. Robust standard errors for the presence of heteroskedasticity in parentheses. ${ }^{* * *}$ Significant at the $1 \%$ level; ${ }^{* *}$ significant at the $5 \%$ level; ${ }^{*}$ significant at the $10 \%$ level. 
Table 9: Estimates of the log-wage premia (wage 'returns') for an UG degree (BCS70) - CFA

\begin{tabular}{|c|c|c|c|c|c|c|}
\hline \multirow{3}{*}{$\begin{array}{l}\text { Return to } \\
\text { UG degree }\end{array}$} & \multicolumn{6}{|c|}{ Specification II } \\
\hline & \multicolumn{3}{|c|}{ Men } & \multicolumn{3}{|c|}{ Women } \\
\hline & Coef. & & s.e. & Coef. & & s.e. \\
\hline UG degree & 0.143 & $* * *$ & 0.044 & 0.176 & $* * *$ & 0.035 \\
\hline & -0.0003 & & 0.0069 & 0.0001 & & 0.0004 \\
\hline N.obs. & & 961 & & & 1,017 & \\
\hline $\mathrm{R}^{2}$ & & 0.126 & & & 0.165 & \\
\hline \multicolumn{7}{|c|}{ F-test father's education (p-value) } \\
\hline - Education equation & & 0.015 & & & - & \\
\hline - Log-wage equation & & 0.726 & & & - & \\
\hline \multicolumn{7}{|c|}{ F-test mother's education (p-value) } \\
\hline - Education equation & & - & & & 0.000 & \\
\hline - Log-wage equation & & - & & & 0.756 & \\
\hline
\end{tabular}

Note. The dependent variable is the natural logarithm of gross hourly wages. Standard errors are bootstrapped with 500 replications since the model is estimated in two stages. ${ }^{* * *}$ Significant at the $1 \%$ level; ${ }^{* *}$ significant at the $5 \%$ level; * significant at the $10 \%$ level. 
Table 10: Estimates of the log-wage premia (wage 'returns') by degree class (BCS70) - CFA

\begin{tabular}{|c|c|c|c|c|c|c|}
\hline \multirow{3}{*}{$\begin{array}{l}\text { Return to } \\
\text { UG degree }\end{array}$} & \multicolumn{6}{|c|}{ Specification II } \\
\hline & \multicolumn{3}{|c|}{ Men } & \multicolumn{3}{|c|}{ Women } \\
\hline & Coef. & & s.e. & Coef. & & s.e. \\
\hline 'Good' degree & 0.186 & $* * *$ & 0.052 & 0.211 & $* * *$ & 0.037 \\
\hline Lower degree class & 0.112 & $* *$ & 0.044 & 0.142 & $* * *$ & 0.043 \\
\hline$\rho \sigma$ & 0.0002 & & 0.0035 & 0.0014 & & 0.0017 \\
\hline N.obs. & & 957 & & & 1,017 & \\
\hline $\mathrm{R}^{2}$ & & 0.128 & & & 0.1685 & \\
\hline \multicolumn{7}{|c|}{ F-test father's education (p-value) } \\
\hline - Education equation & & 0.014 & & & - & \\
\hline - Log-wage equation & & 0.719 & & & - & \\
\hline \multicolumn{7}{|c|}{ F-test mother's education (p-value) } \\
\hline - Education equation & & - & & & 0.000 & \\
\hline - Log-wage equation & & - & & & 0.707 & \\
\hline
\end{tabular}

Note. The dependent variable is the natural logarithm of gross hourly wages. Standard errors are bootstrapped with 500 replications since the model is estimated in two stages. ${ }^{* * *}$ Significant at the $1 \%$ level; ${ }^{* *}$ significant at the $5 \%$ level; *significant at the $10 \%$ level. 
Table 11: Estimates of the log-wage premia (wage 'returns') using PSM-ATT (BCS70)

\begin{tabular}{|c|c|c|c|c|c|c|c|c|}
\hline \multirow{4}{*}{$\begin{array}{l}\text { Return to } \\
\text { UG degree } \\
\text { PSM-ATT } \\
\text { PS) }^{(a)}\end{array}$} & \multicolumn{8}{|c|}{ Specification II } \\
\hline & \multirow{3}{*}{$\begin{array}{c}\text { N.obs. } \\
672\end{array}$} & \multirow{2}{*}{\multicolumn{2}{|c|}{$\begin{array}{l}\text { Men } \\
\text { Coef. }\end{array}$}} & \multirow{3}{*}{ s.e. } & \multirow{3}{*}{$\begin{array}{c}\text { N.obs } \\
664\end{array}$} & \multirow{2}{*}{\multicolumn{2}{|c|}{$\begin{array}{l}\text { Women } \\
\text { Coef. }\end{array}$}} & \multirow{3}{*}{$\begin{array}{c}\text { s.e. } \\
0.071\end{array}$} \\
\hline & & & & & & & & \\
\hline & & 0.123 & $*$ & & & 0.149 & $* *$ & \\
\hline OLS on common support & 672 & 0.125 & $* * *$ & 0.043 & 664 & 0.158 & $* * *$ & 0.036 \\
\hline OLS & 675 & 0.124 & $* * *$ & 0.043 & 669 & 0.161 & $* * *$ & 0.036 \\
\hline \multicolumn{9}{|l|}{ PSM diagnostics } \\
\hline$\%$ obs. in common support & \multicolumn{4}{|c|}{99.56} & \multicolumn{4}{|c|}{99.25} \\
\hline Balancing property $^{(b)}$ & \multicolumn{4}{|c|}{ OK } & \multicolumn{4}{|c|}{ OK } \\
\hline Probit pseudo $\mathrm{R}^{2(c)}$ & \multicolumn{4}{|c|}{0.170} & \multicolumn{4}{|c|}{0.244} \\
\hline
\end{tabular}

Note. The outcome variable is the natural logarithm of gross hourly wages. (a) Average Treatment on the Treated (ATT) computed using Propensity Score Matching (PSM), in particular Nearest Neighbour Matching with replacement, see Becker and Ichino (2002). Bootstrapped standard errors, 500 replications. (b) test for the balancing property, see Becker and Ichino (2002), in particular the balancing property is not rejected only in the case it holds for every single variable using to compute the propensity score. ${ }^{(c)}$ Pseudo $R^{2}$ of the probit model used to compute the propensity scores, which includes all the explanatory variables listed in specification II in section $6.1 .{ }^{* * *}$ Significant at the $1 \%$ level; ${ }^{* *}$ significant at the $5 \%$ level; *significant at the $10 \%$ level. 